\title{
DENSITOMETRIA EM AEROFOTOGRAFIAS COLORIDAS NORMAIS E INFRAVERMELHAS RELACIONADA AS CARACTERISTICAS DAS CORES DE TREES LATOSSOLOS
}

\author{
PEDRO LUIZ DONZELI \\ Pesquisodor Científico \\ Instituto Agronōmico - SP
}

Orientador: Prof. Dr. GERALDO VICTORINO DE FRANCA

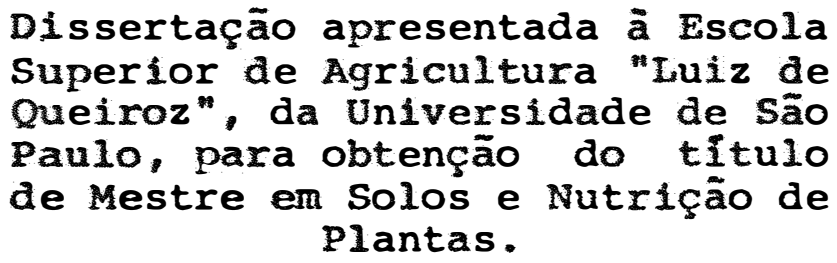

PIRACICABA

ESTADO DE SĀO PAULO - BRASIL NOVEMBRO, 1979 
$-i i-$

Aos meus pais

A minha esposa

As minhas filhas

DEDICO 


\section{AGRADECIMENTOS}

A Empresa Brasileira de Pesquisa Agropecuāria pela concessão de bolsa de estudos para o Curso de pós-Graduação na E.S.A.' "Luiz de queiroz", USP.

Aos Diretores do Instituto de Pesquisas Espaciais e do Instituto Agrônomico do Estado de São Paulo, por fornecerem as condições materiais para realização deste trabalho.

Ao Profo or. Geraldo Victorino de França, do Dep. de Solos da E.S.A. "Luiz de Queiroz" pela orientação.

Ao Pesquisador Cientifico Jorge Vicente chiareni, chefe da Seção de Fotointerpretação, do Instituto Agronômico, pelas facixidades oferecidas.

Ao chefe, técnicos e funcionārios da Estação de Processamento de Imagens do INPE - Cachoeira Paulista, pelas facilidades oferecidas e cooperação técnica, em especial, os senhores: Mārcio Nogueira Barbosa, André Luĩz Pinto Teixeira e à Srta. Vera Lucia Azevedo Silva.

Aos Pesquisadores do INPE Märio Valērio Filho e Natālio Felipe Kobfler pela cooperação técnica, através da qual foi possivel a realização deste trabalho.

Ao Profọ Or. Humberto de campos, pela orientação na anālise estatistica.

As Srtas. Nicia Marcondes Zingra e Girlene Francisco de Souza, funcionārias da seção de Fotointerpretação do Instituto Agronômico, pela confecção dos desenhos e datilografia.

Aos demais funcionārios da seção de Fotointerpretação do Instituto Agronômico e a todos que direta ou indiretamente colaboraram na realização deste trabalho. 


\section{INDICE}

Página

RESUMO

1. INTRODUÇÃO

2. REVISÃO DE LITERATURA $\ldots \ldots \ldots \ldots \ldots \ldots \ldots \ldots \ldots \ldots$

2.1. Energia radiante_Espectro eletromagnético $\quad \cdots \quad 6$

2.2. Tipos de sensores $\ldots \ldots \ldots \ldots \ldots \ldots \ldots \ldots \ldots .8$

2.3. Sensores fotográficos - Filmes $\ldots \ldots \ldots \ldots \ldots .9$

2.4. Conceituação de cor $\ldots \ldots \ldots \ldots \ldots \ldots \ldots \ldots \ldots .9$

2.5. Filmes de reproduções coloridas $\ldots \ldots \ldots \ldots \ldots \quad 15$

2.6. Densidade ótica $\ldots \ldots \ldots \ldots \ldots \ldots \ldots \ldots \ldots \ldots \ldots$

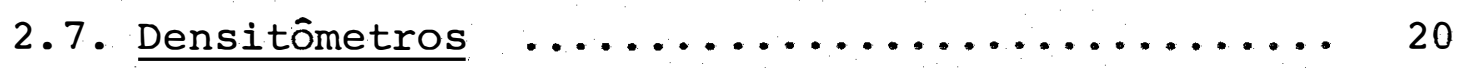

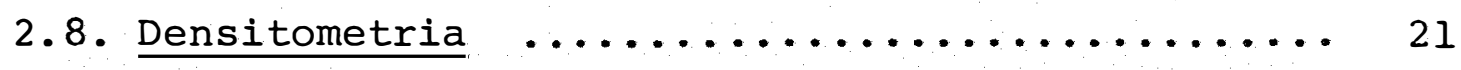

2.9. Sensoriamento multi-espectral fotográfico no levantamento de solos - Tonalidade fotográfica ou

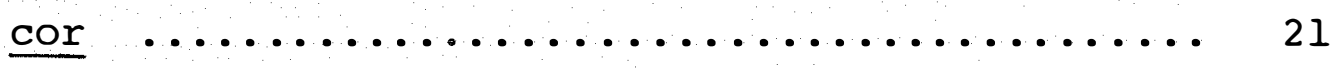

2.10. Relações entre reflectância espectral, cor e outras características físico-químicas dos soIos

3. MAterial e mEtodos $\ldots \ldots \ldots \ldots \ldots \ldots \ldots \ldots \ldots \ldots . . \ldots \ldots$

3.1. Localização geográfica $\ldots \ldots \ldots \ldots \ldots \ldots \ldots . . \ldots$

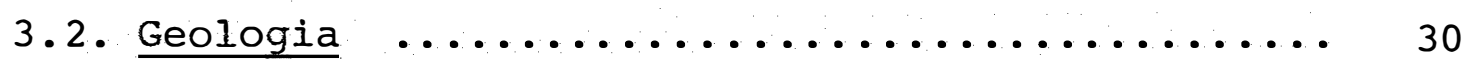

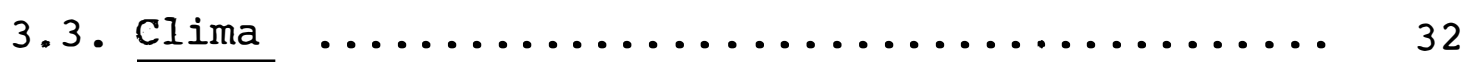




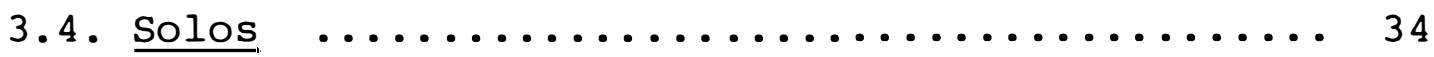

3.5. Material fotográfico ................ 37

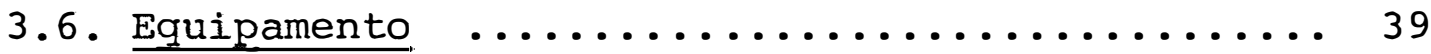

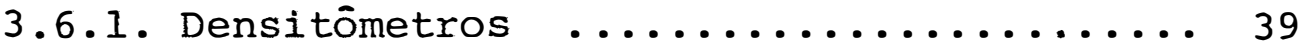

3.6.2. Estereoscópios .................... 39

3.7. Seleção das glebas de solo para estudo ...... 39

3.7.1. Fatores que influenciaram as medidas densitométricas ................. 40

3.7.2. Métodos de seleção das glebas ....... 41

3.8. Preparo das amostras de solo para análise den-

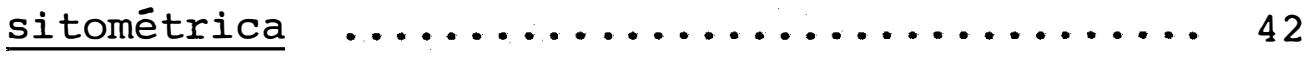

3.9. Anālise densitométrica $\ldots \ldots \ldots \ldots \ldots \ldots \ldots . \ldots 4$

3.10. Determinação das cores Munsell/densitométricas 44

3.11. Análise estatística ............... 46

4. RESULTAdOS E DISCUSSĂO .................. 48

4.1. Interpretação dos valores de densidade ótica de. bandas espectrais $\ldots \ldots \ldots \ldots \ldots \ldots \ldots . \ldots . \ldots 48$

4.2. Avaliação das cores entre cada unidade de solo em confronto com a tabela de Munsell ........ 56

4.2.1. Amostras secas (valores médios - 6 amos-

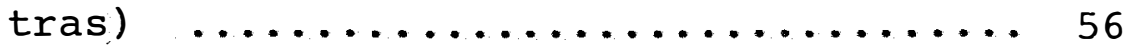

4.2.2. Amostras umedecidas (valores médios - 6 amostras) (...................... 56

4.2.3. Imagens "ektachrome" (valores médios - 6

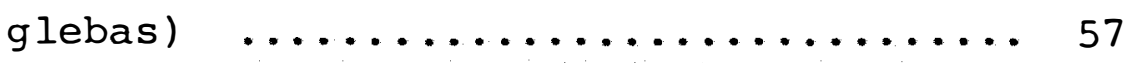

4.2.4. Imagens infravermelho (valores médios -

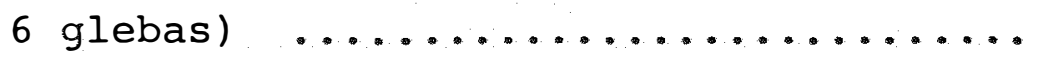


4.3. Avaliação estatística das cores Munsell/densitométrica de cada unidade de solo ......... 58 4.3.1. Cor das amostras de TFSA .......... 58

4.3.2. Cor das amostras umedecidas ........ 59

4.3.3. Cor das imagens "ektachrome" ........ 59

4.3.4. Cor das imagens infravermelho colorido. 59

4.4. Correlações $\ldots \ldots \ldots \ldots \ldots \ldots \ldots \ldots \ldots \ldots \ldots$

4.5. Sugestões para novas pesquisas $\ldots \ldots \ldots \ldots \ldots 76$

5. CONCLUSÕES $\ldots \ldots \ldots \ldots \ldots \ldots \ldots \ldots \ldots \ldots \ldots \ldots \ldots \ldots$

6. LITERATURA CITADA $\ldots \ldots \ldots \ldots \ldots \ldots \ldots \ldots \ldots \ldots \ldots$ 
IISTA DE QUADROS

Quadro

Título

Pãgina

1 Faixas de comprimento de onda e frequência usa das em Sensoriamento Remoto .............. 7

2 Princípio de operação dos filmes coloridos nor mais e falsa cor .................... 16

3 Cronogeologia do substrato da área estudada .. 33

4 Densitometria das amostras de solo (cor seca

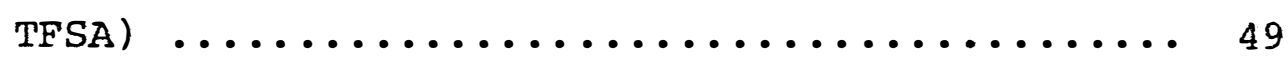

5 Densitometria das amostras de solo (cor úmida) 50

6 Densitometria das imagens - Aerofotos "ekta-

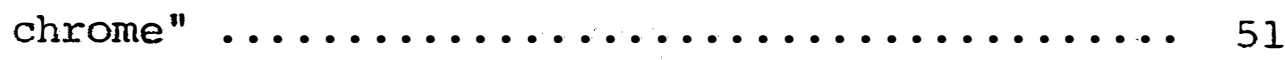

7 Densitometria das imagens - Aerofotos infravermelho colorido .................. 52

8 Cor Munsell/densitométrica das amostras de so-

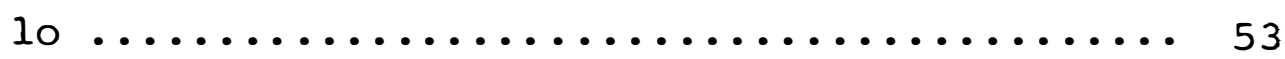

9 Cor Munsell/densitométrica das imagens ...... 54

10 Resultados do teste de Kruskal-Wallis, envolvendo os valores da cor Munsell/densitométrica das amostras de TFSA, para três unidades de so

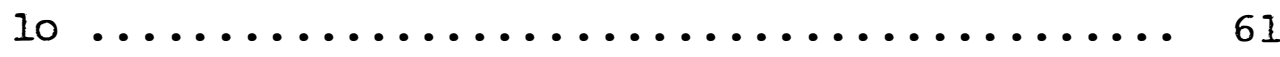

11 Resultados do teste de Kruskal-Wallis, envolvendo os valores da cor Munsell/densitométrica das amostras umedecidas, para três unidades de

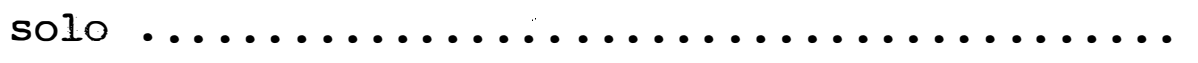


12 Resultados do teste de Kruskal-Wallis, envolvendo os valores da cor Munsell/densitométrica das imagens "ektachrome", para três unidades de solo ........................ 63

13 Resultados do teste de Kruskal-Wallis, envolvendo os valores da cor Munsell/densitométrica das imagens infravermelho colorido para as três unidades de solo ............... 64

14 Matriz de correlações simples - Densitometria em aerofotos "ektachrome" e cor das amostras de TFSA, (valores $R$ para 18 pares de variáveis) 72

15 Matriz de correlações simples - Densitometria em aerofotos infravermelho colorido e cor das amostras de TFSA, (valores $\mathrm{R}$ para 18 pares de variáveis) $\quad \ldots \ldots \ldots \ldots \ldots \ldots \ldots \ldots \ldots \ldots \ldots$ 
LISTA DE FIGURAS

Figura

Título

Pāgina

1 Dimensões psicológicas do diagrama de cor ... 11

2 Técnica para seleção do matiz ............ 13

3 Técnica para determinação do valor e croma .. 14

4 Localização da área estudada (unidades pedológicas e pontos amostrados) (escala 1:100.000). 31

5 Relação funcional entre densidade de drenagem (Dd) e frequência de calhas (Fc) para seis uni dades de solo estudadas ................. 38

6 Relação funcional entre densidade de drenagem (Dd) e a razão de textura (Rt) para seis unidades de solo estudadas .................. 38

7 Disposição das amostras de solo para análise densitométrica .................... 43

8 Relação funcional entre cor (matiz, valor e croma) média das amostras de solo seco (TFSA), (SS), e cor média das correspondentes imagens em fotos "ektachrome" (FE), para as três uni-

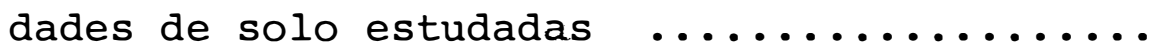

9 Relação funcional entre cor das amostras umedecidas (matiz, valor e croma), (SU), e cor das correspondentes imagens "ektachrome" (FE), para as três unidades de solo estudadas .... 68 
Relação funcional entre densitometria ótica (DS) das amostras de solo (TFSA) e densitometria ótica das correspondentes imagens em fotos "ektachrome" (DF), para 12 leituras médias de 6 repetições para cada unidade de solo es-

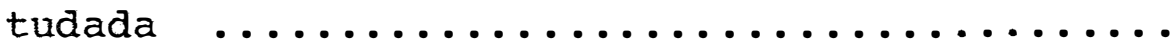

11 Relação funcional entre densitometria ótica (DS) das amostras de solo (solo umedecido) e densitometria ótica das correspondentes imagens em fotos "ektachrome" (DF), para 12 leituras provenientes de 6 repetições para cada unidade de solo estudada ............... 70

12 Relação funcional entre valores de densidade ótica de filtro visual em fotos "ektachrome" (DNE) e medidas de densidade ótica de filtro visual das correspondentes imagens em fotos in fravermelho (DNI) $\ldots \ldots \ldots \ldots \ldots \ldots \ldots \ldots \ldots$ 
RESUMO

Foram realizados estudos de densitometria ótica relacionando características das cores dos horizontes superficiais de solos preparados para plantio e suas respectivas imagens em aerofotografias "ektachrome" e infravermelho $\infty$ lorido.

As unidades de solo são: Latossolo Roxo, Latossolo Vermelho escuro e Latossolo Vermelho Amarelo, todos distróficos, com horizonte "A" moderado, desenvolvidos sobre sedimentos argilosos, e situados na "Depressão Periférica", Região de Limeira-Araras, Estado de são Paulo.

Os valores densitométricos em aerofotografias foram determinados para cada solo, sendo testada sua significância na avaliação das diferenças quantitativas da cor.

A densitometria ótica das aeroimagens possibiIitou a detectação de diferenças entre solos, principalmente quando a cor foi característica diagnóstica, e onde outros tipos de imagens e critérios estudados anteriormente mostraram-se ineficientes.

Foram verificadas altas correlações entre densitometria ótica de faixas espectrais das aeroimagens e a cor Munse11/densitométrica das unidades de solo estudadas. 
SUMMARY

Densitometry on ektachrome and IR
color aerial photographs in rela-
tion to color characteristics of
three latosols.

Studies of optical densitometry were carried out in relation to bare soils superficial horizons color characteristics, and its respective images on ektachrome and IR color aerial photographs. Soil units were: Dark Red, Dusky Red and Red Yellow latosols, all distrofic, with ochric epipedon, developed from clayey sediments, and located in the "Periferic Depression", Limeira-Araras Region, são Paulo state, Brasil.

Densitometric values on aerial images were determined for each soil, and its significance was tested in the avaliation of the color quantitative differences.

The aerial images optical densitometry were able to detected soil differences, mainly when soil color was a diagnostic characteristic, and even when other kind of images and previously studied relief and dranaige patterns were inefficients. 
High correlations were found out between aerial images spectral band optical densities and the Munsell/densitometric color of the studied soil units. 


\section{INTRODUÇÃO}

Com o crescente desenvolvimento da tecnologia do Sensoriamento Remoto, têm sido criadas maiores facilidades para estudosdo meio físico em nosso País, em particular o levantamento dos recursos de solo, com utilização de vários tipos de materiais aerofotográficos em escalas médias e grandes.

Graças aos esforços desenvolvidos e com o aprimoramento da tecnologia, atualmente já se consegue obter imagens aerofotográficas de excepcional qualidade, com utilização de filmes pancromáticos e coloridos, normais ou com sensibilidade no infravermelho.

A utilização de fotografias aéreas ou outros tipos de imagens fotográficas obtidas por vários aparelhos sensores, para mapeamento de solos, torna-se hoje uma técnica imprescindível em nosso meio. Para tanto, é necessário pesquisar as possibilidades dos diferentes materiais e intensificar o desenvolvimento de critérios aplicáveis às nossas condições.

Este trabalho visa o estudo do critério da tonalidade ou cor em aerofotografias "ektachrome" e infravermelho colorido, como registro da reflectância espectral relativa, para três unidades de solo situadas na Província Geo- 
morfológica da Depressão Periférica, nos municípios de Limeira e Araras, Estado de são Paulo.

$$
\text { Pretende-se com a realização deste trabalho, }
$$
testar as possibilidades desses materiais em áreas representativas das unidades de solo, através da caracterização densitométrica das suas cores em correlação com a densidade ótica de faixas espectrais das correspondentes imagens.

A determinação das cores, independentemente dos fatores psico-fisiológicos, possibilita testar a sua significância estatística, em termos de diferença entre solos, com maior rigor.

A área em questão se presta muito bem para objeto desse estudo, uma vez que conta com cobertura aerofotográfica multi-sensorial em diferentes escalas, levantamento de solos em nivel de semi-detalhe e homogeneidade do uso da terra pela cultura da cana-de-açucar.

A cultura da cana-de-açucar apresenta como caracteristica, importante para o presente estudo, a renovação dos talhões ocupados a cada ciclo cultural, sendo este um dos principais fatores que possibilitam a caracterização densitométrica das imagens de glebas de solo preparadas para plantio, em condições homogêneas. 
2. REVISÃO DE LITERATURA

\subsection{Energia radiante - Espectro eletromagnético}

A energia eletromagnética que interessa ao Sensoriamento Remoto pode ser natural, como aquela que provém do sol e da terra, ou artificial como a gerada por radar, laser, etc.

Segundo CARROLI (1973) o sol constitui a fonte natural mais importante, pois sua energia, ao atingir a superfície da terra, origina uma série de fenômenos, como absorção, reflexão, emissão, sob a influência de fenômenos naturais diversos e da composição físico-química dos diferentes materiais que compõem a crosta terrestre.

Qualquer fonte de energia eletromagnētica é definida por um espectro de emissão através de características próprias das ondas eletromagnéticas, como comprimento de onda, frequência, energia, etc.

O espectro eletromagnético se estende desde comprimentos de onda muito curtos, como os raios gama de alta frequência, até as ondas de rádio de baixa frequência e longos comprimentos de onda (Quadro 1 - CARROLL (1973).

A unidade internacional usada para comprimen- 


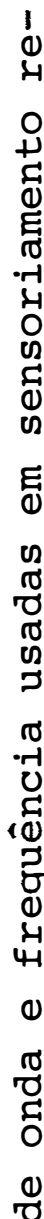

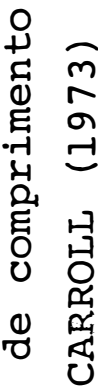

\begin{tabular}{|c|c|c|c|c|c|c|c|c|c|c|c|}
\hline 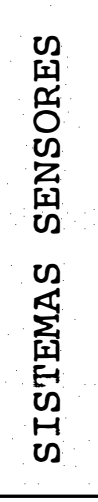 & & $\begin{array}{l}0 \\
0 \\
0 \\
\pi \\
0 \\
0 \\
0 \\
0 \\
0 \\
z\end{array}$ & & 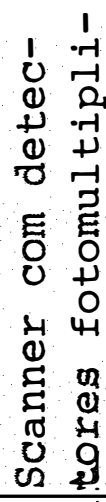 & \begin{tabular}{|l}
$\mid$ \\
\\
\\
\\
0 \\
0 \\
0 \\
0 \\
0 \\
0 \\
0 \\
0
\end{tabular} & 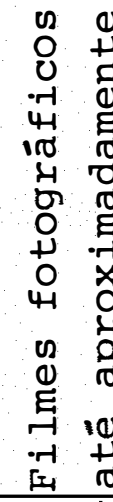 & 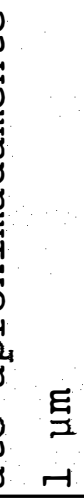 & 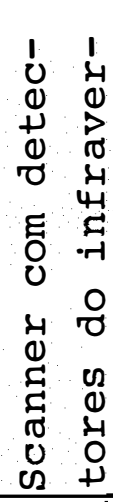 & 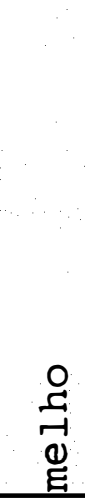 & 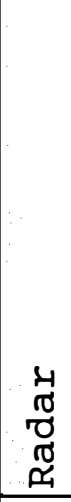 & 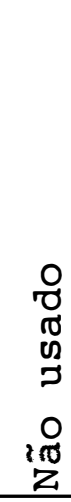 \\
\hline 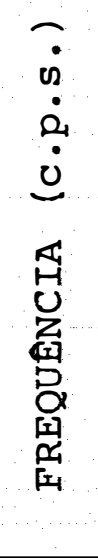 & $i$ & i & 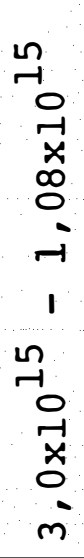 & $\begin{array}{c}n \\
-1 \\
0 \\
-1 \\
x \\
0 \\
0 \\
0 \\
1 \\
n \\
\sim \\
0 \\
-1 \\
x \\
0 \\
0 \\
-1\end{array}$ & 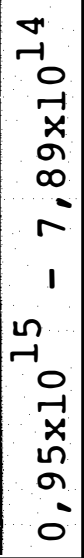 & $\begin{array}{c}\vec{a} \\
-0 \\
0 \\
-1 \\
x \\
0 \\
\infty \\
n \\
1 \\
1 \\
-1 \\
0 \\
-1 \\
x \\
\infty \\
\infty \\
-\end{array}$ & 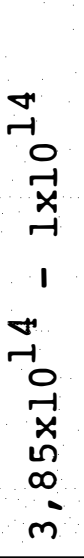 & 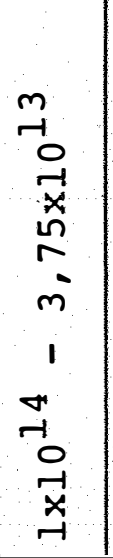 & 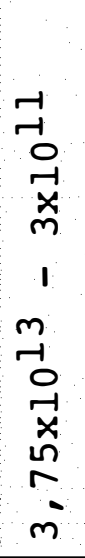 & 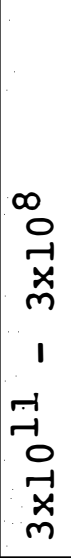 & i \\
\hline 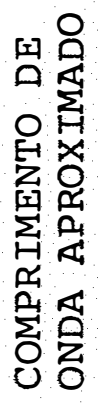 & $\begin{array}{l}\text { E్ } \\
\text { D } \\
\text {-1 } \\
1 \\
\text { 1. } \\
0\end{array}$ & 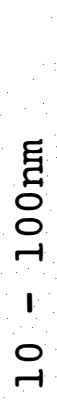 & 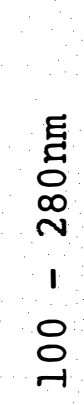 & 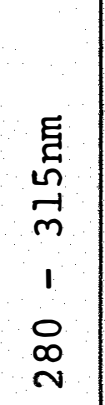 & 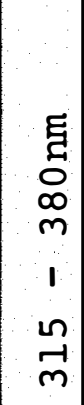 & $\begin{array}{c}E \\
\text { ב } \\
0 \\
\infty \\
N \\
1 \\
0 \\
\infty \\
m\end{array}$ & $\begin{array}{c}E \\
\text { E } \\
0 \\
0 \\
0 \\
\dot{m} \\
1 \\
1 \\
0 \\
0\end{array}$ & 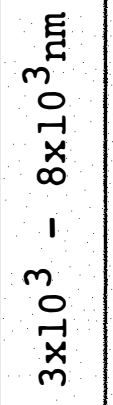 & \begin{tabular}{c} 
E \\
0 \\
0 \\
-1 \\
$\not{7}$ \\
\multicolumn{1}{c}{} \\
1 \\
$m_{0}$ \\
$\underset{-1}{x}$ \\
$\infty$
\end{tabular} & $\begin{array}{c}\tilde{E} \\
0 \\
0 \\
0 \\
1 \\
1 \\
-1 \\
0\end{array}$ & 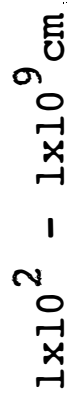 \\
\hline 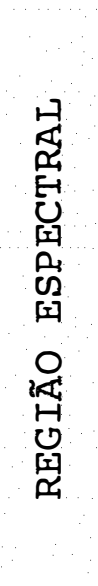 & 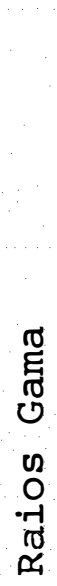 & $\begin{array}{l}x \\
0 \\
0 \\
-1 \\
0 \\
0\end{array}$ & 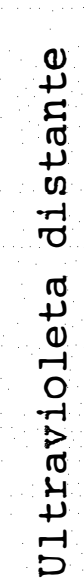 & 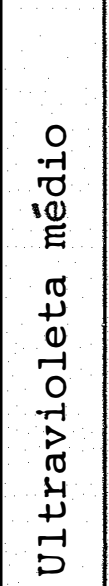 & 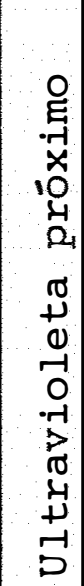 & 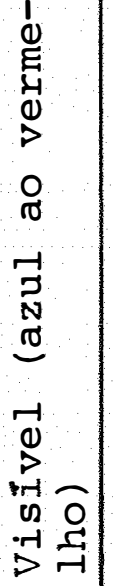 & 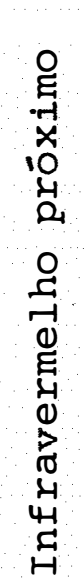 & 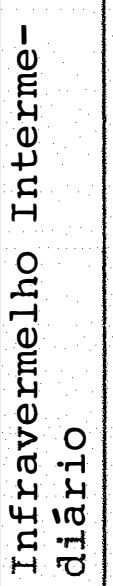 & 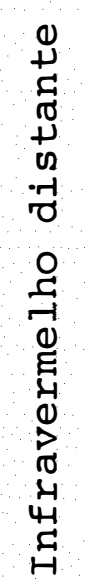 & 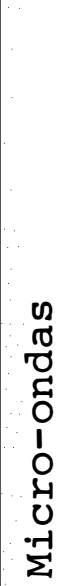 & 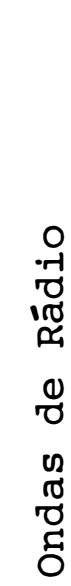 \\
\hline
\end{tabular}


tos de onda é o micrômetro $(\mu \mathrm{m})$, equivalente a $10^{-6} \mathrm{~m}$, ou o nanömetro, equivalente a $10^{-9} \mathrm{~m}$.

\subsection{Tipos de sensores.}

COLWELL (1966) classifica os sensores em "passivos" quando registram a energia solar refletida pela superfície da terra; e "ativos", tais como o radar, quando geram a sua própria energia para iluminar o objeto artificialmente.

Os sistemas sensores são também classificados em "diretos" quando registram a energia sem etapas intermediárias, como por exemplo os sensores fotográficos que produzem imagens da radiação refletida diretamente sobre um filme, por meio de sistemas óticos.

Os métodos "indiretos" são utilizados em comprimentos de onda superiores a 900nm onde não é possível usar filmes fotográficos, diretamente.

Neste caso, a radiação detectada é convertida em impulsos elétricòs, os quais são transformados em um tubo de raios catódicos, em luz visível.

Estes são os sensores imageadores que, em ūltima etapa, registram dados em filmes fotográficos, cujas imagens representam o relativo nível de radiação provinda de vārias superfícies imageadas, em regiões espectrais selecionadas.

Esses mesmos sistemas, assim como outros ditos não imageadores, podem também registrar diretamente a radiação eletromagnētica recebida em fitas magnéticas, as quais podem fornecer dados mais quantitativos e adaptáveis à análise em computador. 


\subsection{Sensores fotográficos - Filmes}

Os sensores fotográficos, como mostra o Quadro 1 - CARROLL (1973) operam na porção visível do espectro eletromagnético $(0,38-0,72 \mu \mathrm{m})$ e em pequena porção do infravermelho próximo $(0,72-0,90 \mu \mathrm{m})$.

o principal elemento, que exerce o papel de detector do sistema fotográfico, são os filmes que respondem ao estímulo espectral da luz que passa pelo filtro e objetiva da câmara aerofotográfica, trazendo a informação sobre os materiais imageados. Os filmes aerofotográficos são reunidos em dois grandes grupos: Pancromáticos e Coloridos, ambos podendo ser, como exposto por HELLER (1971), normais ou sensiveis ao infravermelho, sendo que cada tipo de filme, possui características próprias de sensibilidade espectral definidas pela curva de sensibilidade espectral característica.

\subsection{Conceituação de cor}

Conforme expõe AMARAL (1975), a cor é uma das propriedades mais dificeis de conceituar, pois ela depende não apenas de fatores físicos, mas também de fatores fisiológicos e psicológicos.

A cor de um objeto à luz solar, constitui uma de suas propriedades, sendo que essa cor poderá mudar, de acordo com o tipo de iluminação a que é exposto esse objeto. Newton, ao decompor a luz branca através de um prisma e ao recompô-la por meio de lentes, foi o primeiro a explicar a verdadeira natureza da luz e explicar porque diferentes objetos possuem diferentes cores, isto é, os objetos aparecem coloridos à Iuz branca porque refletem alguns de seus componentes espectrais com maior intensidade que outros.

Para representação gráfica das cores, foram desenvolvidos métodos como os de Munsell (1961), ISCC - NBS 
(Inter-Society Color Council - National Bureau of Standards) e CIE (Comission Internationale de L'Eclairage citados por RIB (1968).

O método Munsell representa as cores num diagrama tridimensional, conforme ilustra a Figura 1 , com base nas variáveis: tonalidade, brilho e saturação. O diagrama, no seu todo representando a tonalidade é dividido em 5 zonas denominadas R (Red), Y (Yellow), G (Green), B (Blue) e P (Purple). Estas zonas são ainda subdivididas em 5 matizes intermediārios $Y R, G Y, B G, P B$ e RP.

Cada uma dessas 10 zonas são numeradas em sequência de 0 - 100 (em intervalos iguais de valor 10) a partir de $R$ até $P$, constituindo o número do matiz de Munsell.

$$
\text { o croma ou saturação é representado também }
$$

por faixas radiais a partir do eixo de neutralidade. 0 número representativo do croma varia de $0-20$, na dependência do matiz e do valor (brilho).

o eixo vertical (valor) é dividido em 10 partes iguais de (0) zero para o preto na base, até o branco no ápice. As designações são dadas na seguinte ordem: matiz, valor e croma.

O método ISCC-NBS é uma modificação do sistema Munsell, sendo puramente descritivo, com cada cor recebendo um nome específico. O método CIE define as cores com base em sua tonalidade, saturação e brilho, porém em um diagrama bidimensional (diagrama de cromaticidade).

STRANDBERG (1968) expõe sobre a teoria das cores, demonstrando que todas as cores podem ser obtidas pela combinação de apenas três cores monocromáticas, denominadas cores primárias, vermelho, verde e azul. Os objetos que refletem quase totalmente a luz branca são brancos e os que refletem a luz vermelha, absorvendo o azul e o verde, são 


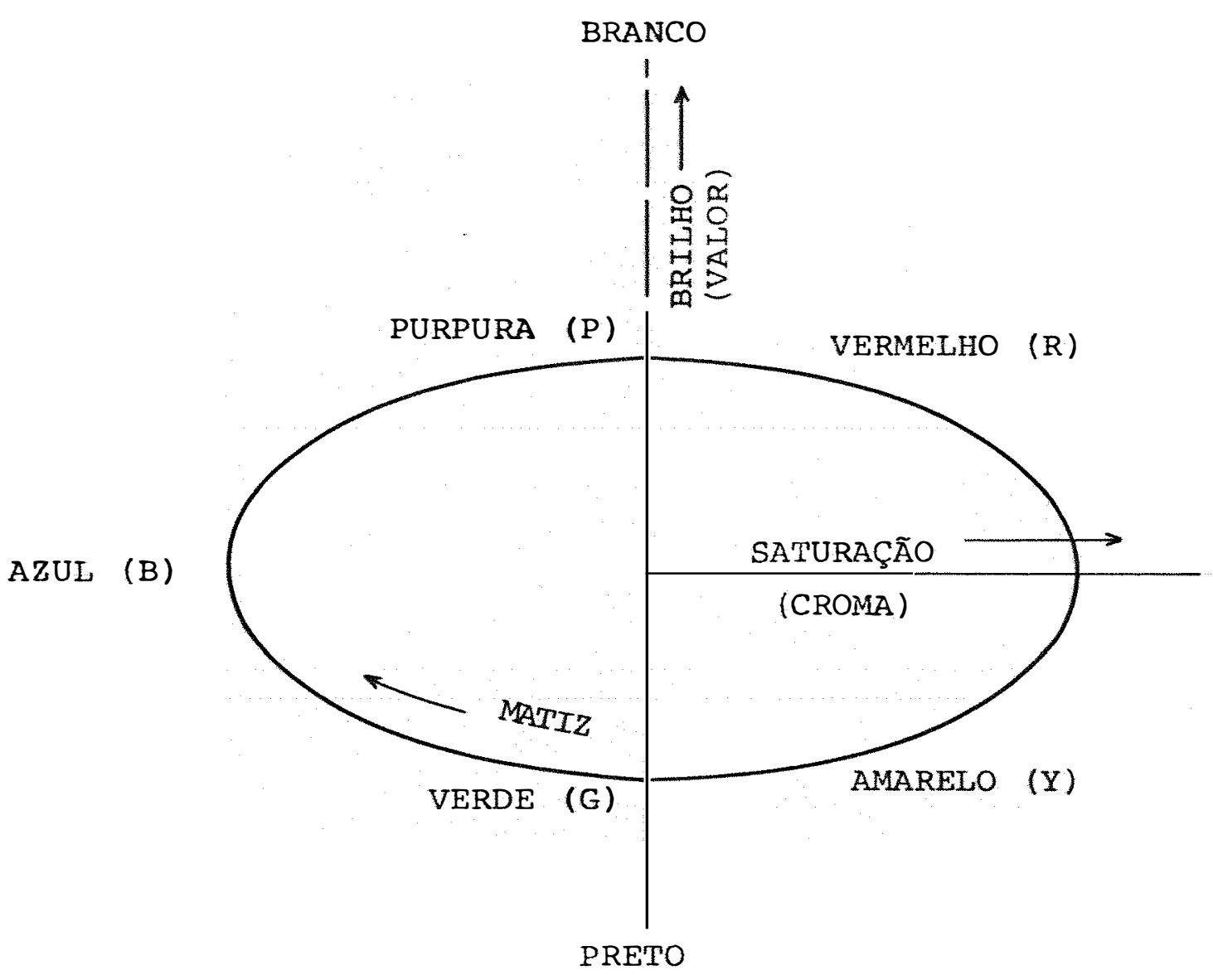

Fig.1 Dimensōes psicológicas do diagrama de cor (Extraído de RIB, 1968). 
vermelhos. No caso de superfícies amarelas, estas refletem dois componentes da luz branca, o verde e o vermelho, absorvendo $\circ$ azul. A mistura do verde e vermelho reproduz $\circ$ amarelo.

As três cores aditivas primárias, vermelho, verde e azul, combinam-se duas a duas formando as cores subtrativas cíano, magenta e amarelo. Quando somadas' as três cores primárias reproduzem a luz branca. A televisão colorida emprega este método de combinação aditiva de cores primárias onde feixes de luz vermelha, verde e azul são combinados de modo a formar todas as cores.

Pode-se partir também das cores secundárias amarelo, magenta e cíano para se reproduzir as cores primárias, sendo que as diversas cores poderão ser obtidas pelo processo subtrativo, através do qual as cores primárias são subtraidas da luz branca. Este é o processo utilizado na fotografia colorida convencional e impressão a cores.

Conforme comenta AMARAL (1975), a cor de um objeto pode ser medida por espectrofotometria. Nesta técnica o objeto é iluminado por uma fonte de luz padrão (por eexemplo luz de tungstênio) e a radiação refletida é decomposta por prismas, sendo medida a intensidade dos componentes espectrais. RIB (1968) desenvolveu uma técnica para determinação dos três atributos que caracterizam a cor de Munsell. Esta consistiu em se obter medidas densitométricas em quatro filtros para cada amostra de cor contida na carta de cores de Munsell. Dois ábacos foram desenvolvidos, sendo um para a determinação do matiz e outro para determinação do valor e croma, conforme ilustram as Figuras 2 e 3 . 


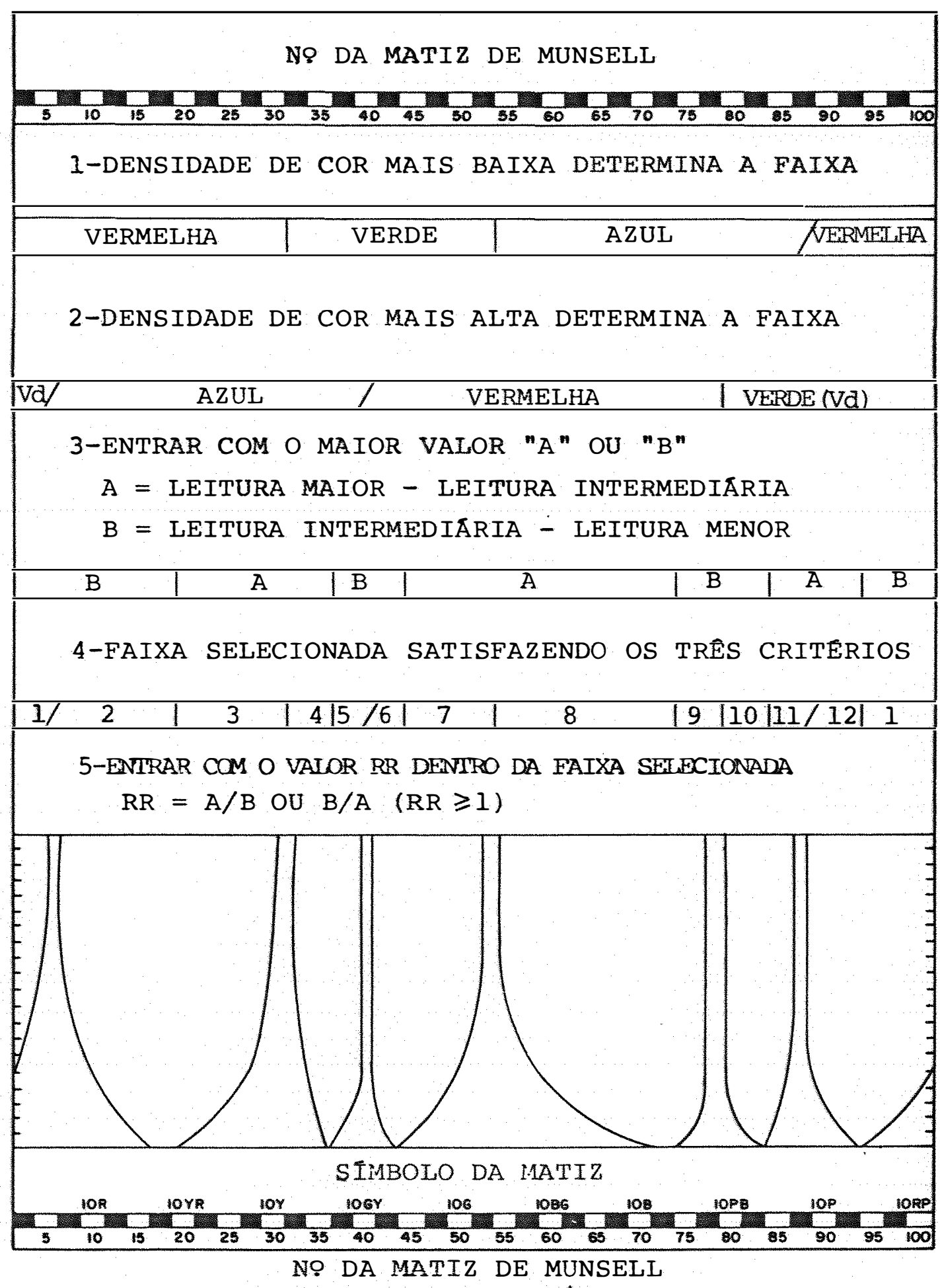

Fị.2 Técnica para seleção do matiz (Extraido de RIB, 1968) 
Leitura do filtro visual (x 100) $\longrightarrow$

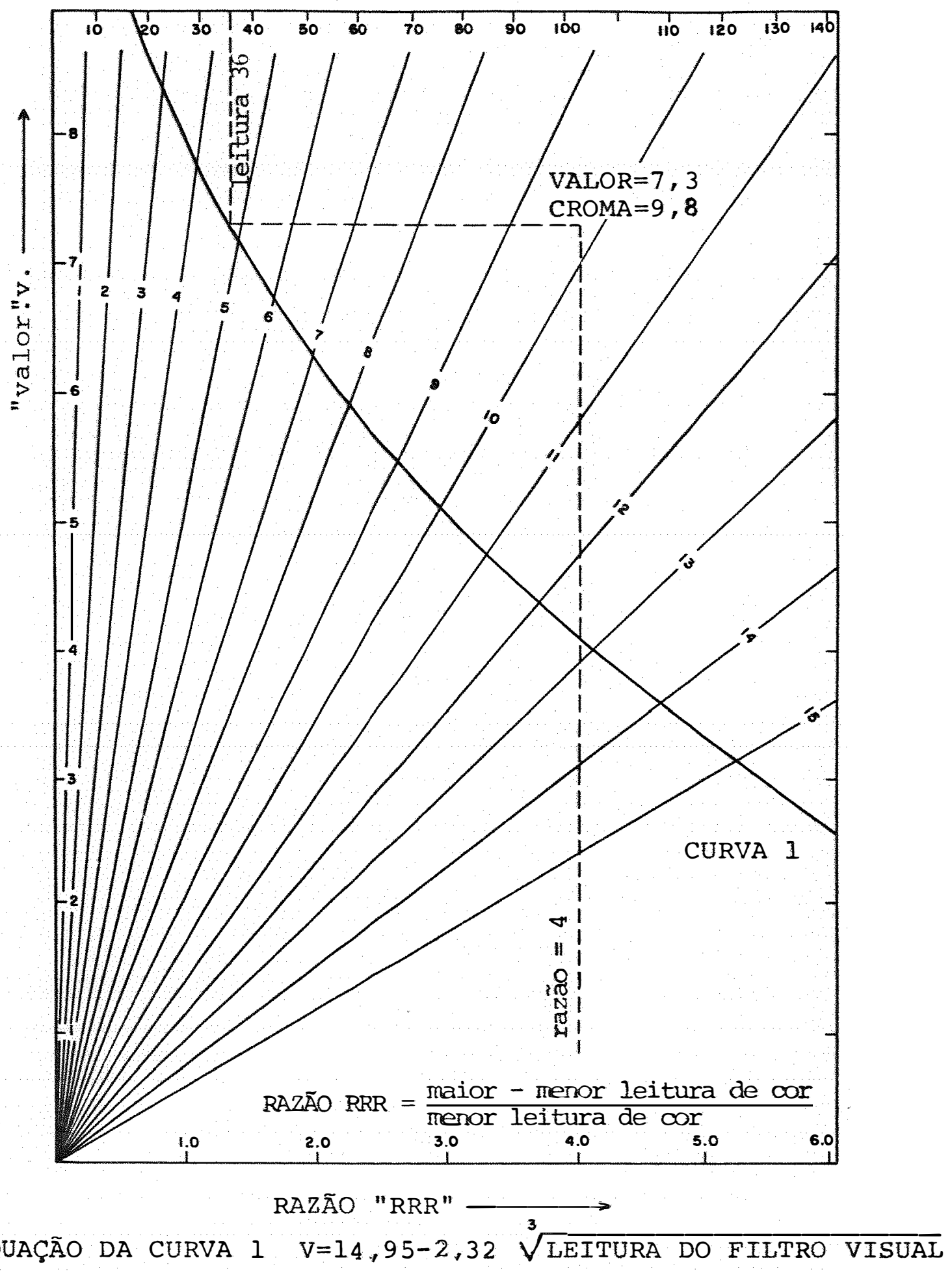

Fig.3 Técnica para determinação do Valor e Croma (Extraído de RIB, 1968) 
2.5. Filmes de reproduções coloridas

FORSGARD e WHITTEMORE (1968) expõem sobre os filmes coloridos utilizados em fotointerpretação, como tambēm os preto e branco, que são classificados em normais ou sensiveis ao infravermelho. Podem abranger no espectro eletromagnētico desde $o$ ultravioleta próximo, passando pelo visivel até o infravermelho próximo. Enquanto os filmes preto-e-branco possuem apenas uma emulsão sensivel à luz sobre uma base de acetato ou poliester, os filmes coloridos são compostos de três emulsões sensiveis às três cores primárias, azul, verde e vermelho. Estes filmes possuem, como os pretoe-branco uma camada anti-halo, que absorve a energia luminosa que atravessa as emulsões, evitando que ela sofra reflexão, voltando para a emulsão e causando o aparecimento de imagens fantasmas. Como as três emulsões do colorido normal apresentam sensibilidade na região do azul, há necessidade de um filtro amarelo entre a primeira camada e as seguintes para impedir que esta luz sensibilize as outras duas camadas. No filme colorido sensivel ao infravermelho, a camada de emulsão sensível ao azul è substituída por uma sensível ao infravermelho. Neste caso, um filtro amarelo è usado em frente à objetiva da câmara, evitando que esta luz atinja o filme.

Conforme AMARAL (1975), as fotografias coloridas são baseadas em três premissas:

a) As cores como são vistas pelo olho humano podem ser reproduzidas pela mistura de apenas três cores primárias.

b) As emulsões fotográficas são constituídas de modo a responder seletivamente à cada uma das três cores.

c) Existem reações químicas capazes de produzir pigmentos que irão absorver cada uma daquelas três cores. 
As cores dos pigmentos das três camadas dos filmes coloridos devem, portanto, corresponder às cores subtrativas secundārias, ou seja, cíano absorvendo o vermelho, magenta absorvendo o verde, e amarelo absorvendo o azul. Segundo HELLER (1971), o princípio de operação para o filme colorido normal e o filme sensível ao infravermelho é representado pelo Quadro 2.

Quadro 2. Princípio de operação dos filmes colorido normal e falsa cor. HELLER (1971)

COLORIDO NORMAL

\begin{tabular}{l|l|l|l|c}
\hline Região Espectral & Azul & Verde & Vermelho & Infravermelho \\
\hline $\begin{array}{l}\text { Sensibilidade } \\
\text { Cor dos Pigmentos }\end{array}$ & Azul & Verde & Vermelho & Amarelo \\
das camadas & Magenta & Cíano & \\
\hline $\begin{array}{l}\text { Cor resultante } \\
\text { nas fotos }\end{array}$ & Azul & Verde & Vermelho & \\
\hline
\end{tabular}

FALSA COR

\begin{tabular}{l|l|l|l|l}
\hline Região Espectral & Azul & Verde & Vermelho & Infravermelho \\
\hline $\begin{array}{l}\text { Sensibilidade com } \\
\text { filtro amarelo }\end{array}$ & -- & Verde & Vermelho & Infravermelho \\
\hline $\begin{array}{l}\text { Cor dos Pigmentos } \\
\text { das camadas }\end{array}$ & -- & Amarelo & Magenta & Cíano \\
\hline $\begin{array}{l}\text { Cor resultante } \\
\text { nas fotos }\end{array}$ & -- & Azul & Verde & Vermelho \\
\hline
\end{tabular}




\subsection{Densidade ótica}

Conforme definição da KODAK (1971), a absorção da luz pela imagem fotográfica é expressa em termos de densidade ótica.

A transmitância, ao contrārio, expressa a quantidade de luz que pode passar através desse filme. O termo densidade é usado preferencialmente em fotografia, porque a diferenciação tonal expressa em unidades de densidade é idêntica à maneira pela qual o olho humano percebe essas diferenças. No caso de cores opacas (cópias em papel) a transmitância é nula, avaliando-se pela reflectância a densidade da imagem.

A densidade é uma função logarítmica, sendo definida para imagens preto-e-branco, como o logarítmo da razão entre a luz incidente e a luz transmitida ou refletida (opacidade - OP). A densidade é também o logarítmo da recíproca da transmitância (T).

$$
\begin{aligned}
& \mathrm{OP}=\frac{\mathrm{P}_{\mathrm{O}}}{\mathrm{P}}=\frac{1}{\mathrm{~T}} \\
& \mathrm{D}=\log \mathrm{OP}=\log \frac{\mathrm{P}_{\mathrm{O}}}{\mathrm{P}}=\log \frac{1}{\mathrm{~T}}
\end{aligned}
$$

Onde: $P_{0}$ e $\mathrm{P}$ são os fluxos de luz incidente e transmitida, respectivamente, e $T$ a transmitância.

Porém, nas imagens coloridas o conceito de densidade é mais complexo, como explica SCARPACE (1978). Sendo o fluxo incidente e a densidade dependentes do comprimento de onda $(h)$, o fluxo de luz transmitida através do filme 
pode ser expresso pela equação:

$$
P(\Lambda)=P_{O}(k) 10^{-D}(k)
$$

Para todo $P_{O}(K)$ incidente em um filme colorido corresponde um $P(\Lambda)$, transmitido através deste, que pode ser calculado.

A equação (2) representa o fluxo transmitido através de uma determinada camada do filme colorido. Sendo o filme colorido composto das camadas cíano (C), magenta (M) e amarelo ( $A$ ), além da camada da base (B), sobre a qual estão assentadas estas outras camadas, a equação dofluxo transmitido em função da densidade pode ser expresso como segue:

$$
\mathrm{P}(h)=\mathrm{PO}(\Lambda) 10^{-}[\mathrm{DB}(\kappa)+\mathrm{DC}(\Lambda)+\mathrm{DM}(\Lambda)+\mathrm{DA}(\kappa)]
$$

Os termos que compõem o expoente da equação (3), são denominados densidades analíticas e não podem ser avaliadas diretamente, sendo que correspondem à densidade integral $D(\Lambda)$ da equação $(4)$.

$$
\mathrm{D}(\Lambda)=\mathrm{DB}(\Lambda)+\mathrm{DC}(\Lambda)+\mathrm{DM}(\Lambda)+\mathrm{DA}(\Lambda)
$$

Desde que a densidade é função do comprimento de onda e considerando as equações (3) e (4), ela seria representada da seguinte maneira:

$$
D\left(\kappa_{a}\right)=\log \frac{P_{O}\left(\kappa_{a}\right)}{P\left(\Lambda_{a}\right)}=\log \frac{1}{T\left(x_{a}\right)}
$$

Onde $h_{a}$ representa um comprimento de onda determinado. A densidade assim expressa é denominada densidade espectral. 
Porém, quando as densidades são avaliadas através de um filtro, representado por determinada curva de transmitância espectral, estas são denominadas densidades de faixas espectrais (broad band densities).

Para satisfazer os termos da equação (5) essas densidades devem ser avaliadas com filtros abrangendo estreita faixa espectral, sendo então denominadas densidades espectrais.

No caso dos filtros que abrangem larga faixa espectral, a densidade assim determinada é função não só do fluxo de luz incidente e transmitido, mas também uma função da transmitância do filtro e sensibilidade do densitômetro.

$$
D_{f}=\log \frac{\int \mathrm{P}_{\mathrm{O}}(\Lambda) \cdot \mathrm{F}(\Lambda) \cdot \mathrm{S}(\Lambda) \mathrm{d}(\Lambda)}{\int \mathrm{P}(\Lambda) \cdot \mathrm{F}(\Lambda) \cdot \mathrm{s}(\Lambda) \mathrm{d}(\Lambda)}
$$

onde,

$D_{f}=$ densidade da faixa espectral medida

$F(\Lambda)=$ função da transmitância do filtro

$S(\Lambda)=$ sensibilidade relativa do densitômetro ao fluxo de luz

A integral se estende por todo comprimento de onda no qual o densitômetro é sensível.

SCARPACE (1978) comenta que o tipo de densidade mais conveniente para fotointérprete seria uma densidade analítica espectral. Porém, a medida dessa densidade somente seria possivel, caso se pudesse separar apenas uma simples camada de cor sobre a base do filme.

Para o fotointérprete, é possivel avaliar uma densidade integral espectral como a da equação (5), sendo 
que sua relação com a densidade analítica espectral é:

$$
D\left(\Lambda_{a}\right)=D B\left(\Lambda_{a}\right)+D C\left(\Lambda_{a}\right)+D M\left(\Lambda_{a}\right)+D A\left(K_{a}\right)
$$

A equação (7), seria semelhante à equação (4), porém a um comprimento de onda determinado.

Alguns pesquisadores como Sant e Jackson, citados por SCARPACE (1978), advertem que a equação (4) não descreve exatamente as relações propostas, desde que existe uma interação entre camadas em um filme de múltiplas camadas (colorido).

Quando o objetivo é determinar densidades de cada camada, o problema torna-se realmente mais complexo.

\subsection{Densitômetros}

O manual da KODAK (1971) define os densitômetros como instrumentos utilizados para medir densidades. Esses aparelhos procedem uma comparação por meio de uma fotocélula entre a amostra e um padrão de densidade conhecida.

Os densitômetros empregam luz branca como fluxo incidente, podendo detectar a luz transmitida diretamente ou através de determinados filtros coloridos.

Conforme descrição de SCARPACE (1978), na dependência da geometria ótica dos aparelhos, estes podem medir tanto a densidade especular, como a densidade difusa. Se o feixe de luz incidente é colimado e o fluxo transmitido é medido através de uma pequena abertura, a densidade medida é especular, sendo este o caso dos microdensitômetros. No outro caso, o feixe de luz incidente pode ser difuso ou colimado, porém o fluxo transmitido é medido com uma tolerância angular.

Os densitômetros de densidade difusa são lar- 
gamente usados pelos laboratórios e industrias fotográficas, para controle de processamento dos filmes. Na maioria das aplicações em sensoriamento remoto são utilizados os densitômetros de densidade especular.

Os densitômetros também podem ser de transmissão ou reflexão, para medidas em transparências ou em imagens opacas, respectivamente.

\subsection{Densitometria}

Segundo SCARPACE e FRIEDERICHS (1978), a cor presente na imagem é relacionada à quantidade de luz incidente no filme quando exposto. Para caracterizar a energia incidente é necessária uma caracterização da cor de cada camada. A caracterização mais exata da cor é feita através da densitometria analítica à partir de densidades espectrais ou de bandas espectrais.

Conforme RIB (1968), nas medidas de densidades efetuadas com filtros há uma seleção do feixe de luz incidente dentro de determinada faixa do espectro eletromagnético.

O filtro vermelho, por exemplo, absorve os raios azuis e verdes, selecionando o comprimento de onda da luz vermelha. No caso dos densitômetros de transmissão, a luz vermelha incide no filme, cuja imagem proporcionará valores de transmitância para esta luz, na dependência da quantidade de pigmentos coloridos em cada uma das três camadas do filme. Pela transmitância é avaliada a densidade.

2.9. Sensoriamento multi-espectral fotográfico no levantamento de solos - Tonalidade fotográfica ou cor 
base do sensoriamento multi-espectral é o fato de se acreditar que cada material pesquisado é espectralmente único, isto é, possui um comportamento espectral característico. Os padrões de resposta multi-espectral, no caso dos sensores fotográficos, podem ser considerados como a variação tonal das imagens, uma vez que, o brilho relativo registrado nas imagens fotográficas é induzido pela reflexão espectral do objeto imageado.

AMARAL e AUDI (1972) destacam a tonalidade fotográfica diferencial, como importante critério utilizado na fotointerpretação e particularmente na fotopedologia como característica diferencial entre solos, consequente das diferenças espectrais verificadas entre eles.

HOFFER e ANUTA (1972) consideram que a tonalidade fotográfica seja o fator mais importante na interpretação de imagens multi-espectrais.

GARCIA e MARCHETTI (1977), comentam que embora evidenciada a importância de um filme colorido devido ao recurso da cor, há necessidade de se quantificar esse critério através das leituras densitométricas. Estas não se originam de critérios pessoais, podendo ser repetidas a qualquer momento, desde que se utilizem densitômetros perfeitamente calibrados.

RAY $(1960,1963)$ faz considerações sobre o critério da tonalidade fotográfica na análise de fotos aéreas, ressaltando que a avaliação da densidade da imagem por meio de densitômetros, é adequada para comparações entre as diferentes características do terreno, quando se consideram todos os fatores que interferem na medida. Entre eles, esse autor destaca a variação do ângulo de incidência do sol, topografia do terreno, posição relativa da câmara fotográfica, as características e as condições dos solos e vegetação. 
LUEDER (1959) dedica um capitulo, sobre tons gríseos em fotos pancromáticas e cor em fotos coloridas e falsa cor, discorrendo sobre os fatores que afetam esses tons classificando-os da seguinte maneira:

1) Fatores do terreno: topografia, solo (umidade e matéria orgânica), rocha, cor da vegetação.

2) Fatores Técnicos: características dos materiais e equipamentos, técnicas de exposição, técnicas de processamento.

3) Fatores Metereológicos e Climatológicos: neblina, nuvens, ângulo do sol, estação do ano.

STEINER e HAEFNER (1965) discutem a distorção tonal, ou o problema da maior iluminância próximo ao centro ótico, causado pelo sistema de lentes, afetando as medidas densitométricas. Os autores propõem soluções: restringir o campo de observação nas fotos ou introduzir correções baseadas nas funções da distorção.

A reflectância espectral diferencial entre os solos, a qual é mostrada como contrastes tonais em aerofotografias, é representada segundo MYERS (1979), na porção do

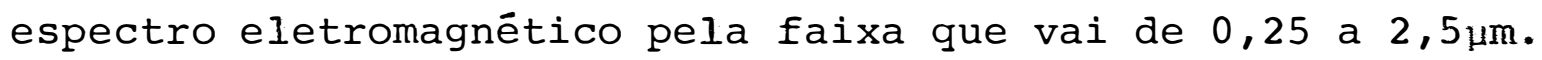

VALERIO FILHO et alii (1976) estudaram alguns critérios aplicáveis a mapeamento de solos usando imagens orbitais, entre os quais, a tonalidade mostrou-se eficiente. Nesse trabalho, foram também avaliadas as respostas espectrais dos grandes grupos de solos estudados, com o emprego do "Ground radiometer Spectrofotometer" e "Image 100".

LUEDER (1959) ressalta que, na avaliação do critērio da tonalidade e cor, levar em consideração que o olho humano é incapaz de dicernir todas as variações de densidade registradas nas fotos, sendo a sensibilidade dos densitômetros muito superior à do olho humano.

A equipe de Pedólogos do SOIL CONSERVATION 
SERVICE (1966), adverte sobre os fatores que interferem no registro dos tons gríseos e cor em aerofotos, destacando entre eles a declividade do terreno, que pode afetar a reflectância espectral.

CIPRA (1973), pesquisando imagens multi-espectrais do satélite ERTS-l, analisando entre outros o critério da tonalidade, fez comparações dessas imagens com mapas de levantamento de solos detalhados, concluindo que as imagens do canal 7 com sensibilidade na faixa do infravermelho próximo foram as mais eficientes para evidenciar diferenças entre solos.

Em outro trabalho, CIPRA et alii (1972) demonstraram a viabilidade para mapeamento de solos com imagens multi-espectrais de um vôo realizado a 1.500 metros de altitude, analisando a resposta tonal em diferentes porções do espectro, em comparação com métodos tradicionais de levantamento de solos.

MATHEUS et alii (1973) analisaram imagens multi-espectrais obtidas a bordo de aeronaves, que se mostraram promissoras tanto na precisão como no tempo de preparação de mapas de levantamento de solos. Quatro glebas de solo nu, cuja área variava de 8,5 a 30,0 hectares, foram selecionadas de uma linha de vôo de $72 \mathrm{Km}$. As propriedades de reflectância da superfície foram classificadas usando técnicas de padrão de reconhecimento. Por computação foram impressos mapas de distribuição espacial das classes espectrais de solos, comparadas às condições de campo. Vários tipos de solos puderam ser separados por esse processo.

CARNEIRO e AZOLIN (1976) realizaram estudos objetivando analisar comparativamente a utilização de imagens multi-espectrais do satélite ERTS-l e fotos aéreas pancromáticas para levantamento de solos, concluindo que a composição colorida "Falsa cor" foi a imagem mais informativa para a finalidade em questão, principalmente quando se utilizou a 
tonalidade e coloração entre outros critérios.

MYERS (1979) ressalta que as vantagens das fotografias coloridas para interpretação de solos tornam-se evidentes quando são consideradas as características do solo associadas à sua cor ou quando são usados métodos dedutivos de associação das condições das culturas com as características dos solos.

Numa análise comparativa de fotos "ektachrome" e pancromáticas para levantamento de solos, DOMINGUES (1960) concluiu que as imagens "ektachrome", quando comparadas com as correspondentes imagens pancromáticas, permitem não apenas maior precissão no delineamento das unidades de solo, mas também aumentam a rapidez com que essas unidades são delinedas, exigindo dos fotointérpretes apenas uma alta acuidade visual para cores. Esse mesmo autor encontrou alta correlação entre as cores dos solos amostrados e a cor registrada nas aerofotos coloridas, utilizando para tanto as notações de Munsell.

PARKS et alii (1973), através das respostas tonais características da cobertura vegetal, utilizando análise automática de dados microdensitométricos das transparências positivas do canal 7 do MSS, conseguiram o delineamento de três associações de solo no Tennesse, EUA.

2.10. Relações entre reflectância espectral, cor e outras, características físico-químicas dos solos.

Recentemente, muitos estudos tem sido conduzidos para reconhecimento de padrões de resposta espectral característica de solos, com resultados bastante promissores, onde as unidades de solo são mais facilmente identificadas e discriminadas quando as variações dentro das unidades, são menores que as variações entre elas. Entre esses trabalhos 
pode-se citar o de MONTGOMERY et alii (1976), que mostraram que as propriedades físico-quimicas dos solos, aliadas ao conteúdo de matéria orgânica, estão correlacionadas com a reflectância espectral, sendo que a porção mediana da região do infravermelho foi a melhor porção do espectro eletromagnético para estudar o efeito das propriedades do solo na reflectância.

PAGE (1974), medindo a reflectância espectral de 96 amostras de horizonte superficial de solos através de avaliação diferencial da cor, encontrou resposta altamente correlacionada ao teor de matéria orgânica dentro da faixa de 0 a $5 \%$.

De vários autores pesquisados que desenvolveram trabalhos nesse campo, como PAGE (1974), MONTGOMERY et alii (1976), CIPRA et alii (1971), pode-se concluir que algumas características dos horizontes superficiais dos solos, como os teores de matéria orgânica e de óxido de ferro livre $\left(\mathrm{Fe}_{2} \mathrm{O}_{3}\right)$, e a composição granulométrica, constituem-se em parâmetros altamente correlacionados à reflectância espectral e o respectivo registro tonal das imagens fotográficas representativas desses solos.

Karmanov e Rozhkov, citados por MONTGOMERY et alii (1976), determinaram a cor de solos cultivados através de coeficientes espectrofotométricos que levam em conta a intensidade e composição espectral da radiação refletida pelos solos, e correlacionaram esses valores com as suas características, apresentando as seguintes conclusōes:

A cromaticidade dos solos estudados (Cinnamon Brown soils) está diretamente e linearmente relacionada aos conteúdos de argila e de óxidos de ferro livre e inversamente relacionada ao conteúdo de carbonatos.

A absorção de luz relativa está diretamente relacionada aos conteúdos de humus e de argila e inversamente 
relacionada ao conteúdo de carbonatos.

A absorção de luz relativa está diretamente relacionada aos conteúdos de humus e de argila e inversamente relacionada ao conteúdo de carbonatos.

Obukhov e Orlov (1964), outros autores citados por MONTGOMERY et alii (1976), concluiram através de trabalho semelhante, que a intensidade da reflexão na região de 0,50 - 0,64um é inversamente proporcional ao conteúdo de ferro no solo.

CROWN e PAWLUK (1974) fizeram medidas de reflectância em condições de campo, em glebas de solo nu, usando um espectroradiômetro. Concluiram que a cor do solo foi o principal fator afetando a reflectāncia na porção visível do espectro, enquanto que a configuração da superfície (rugosidade) e o teor de umidade foram os principais fatores afetando a reflectância na porção do infravermelho próximo. Esses autores fizeram, concomitantemente, medidas com un imageador termal, que mostrou o efeito de práticas de manejo mascarando o efeito emissividade (radiação termal). Concluiram também que existe a possibilidade de usar o vigor das plantas cultivadas avaliado através das técnicas por ele empregadas, como indicador de caracteristicas de subsuperfície, principalmente quando os dados forem obtidos em épocas do ano em que as plantas atingiram seu vigor máximo.

Analogamente, CARROLL (1973) afirma que a cor na interpretação de solos pode ser importante quando são usados métodos dedutivos de associação de condições das culturas com as características dos solos.

Analisando o trabalho de diversos autores como CIPRA et alii (1971), BOWERS e HANKS (1965), CONDIT (1970), verifica-se que o teor de umidade influi grandemente na reflectância espectral dos solos, embora essa influência seja 
mais acentuada sobre a amplitude ou a porcentagem de reflectância absoluta de uma dada amostra. Verifica-se que quanto maior o teor de umidade, menor a amplitude da curva de reflectância.

Obukhov e Orlov, citados por MYERS e ALLEN (1968), verificaram que a reflectância espectral dos solos analisados, nas regiões do vermelho e do infravermelho próximo, estava altamente correlacionada à cor do solo, sendo essa porção do espectro a mais favorável para a visualização de diferenças em cor.

Orlov, citado por MYERS (1979), e VALERIO FILHO et alii (1976), verificou que a influência da estrutura do solo na reflectância é maior do que a da textura, sendo que os solos de estrutura mal definida refletem 15 a $20 \%$ mais luz.

CONDIT (1970) procedeu à medida da reflectância espectral de 160 amostras de solos nos EUA, efetuando a medida para dois teores de umidades (seco e ümido), concluindo que os solos puderam ser identificados pela sua "assinatura" espectral, com leituras da sua reflectância em apenas cinco valores de comprimento de onda:

$$
0,45-0,54-0,64-0,74 \text { e } 0,86 \mu \mathrm{m}
$$

MYERS (1979) verificou que numerosas propriedades dos solos influenciam a reflectância de energia eletromagnética, podendo ser citadas as seguintes: minerais presentes no solo, tamanho dos agregados, estrutura, textura, matēria orgânica e óxido de ferro.

Com respeito à influência do tamanho dos agregados na determinação da reflectância, MONTGOMERY et alii (1976) recomenda que se padronize a amostra em peneira de $1 \mathrm{~mm}$ de abertura.

HOFEER e JOHANNSEN (1969) advertem que os so- 
los cultivados tendem a secar na superfície, mesmo após uma chuva, formando uma crosta que afetará as medidas de reflectância, reagindo esse solo como se estivesse seco, quando na verdade pode estar muito úmido em profundidade.

SHIELDS et alii (1968), pesquisando o problema de mensuração espectrofotométrica da cor do solo, encontraram altas correlações entre a cor Munsell/espectrofotométrica e os teores de matéria orgânica e de umidade do solo. MONTGOMERY et alii (1976), após um exame crítico dos trabalhos de vários pesquisadores, apresentam uma tabela que mostra alto grau de correlação, significante ao nível de 1\%, entre o "matiz" e a porcentagem de ferro livre do solo e entre "valor" e porcentagem de argila ou conteúdo de matéria orgânica. Entretanto não foi observada relação significante entre "croma" e qualquer das características de solo estudadas.

BOWERS e HANKS (1965) fizeram considerações sobre as elevadas temperaturas dos solos escuros. Este fato é atribuido à grande absorção que esses solos apresentam de energia solar radiante. Isso indica que a reflectância é menor para esse tipo de solo, desde que absorção + reflexão + transmissão $=1$, e que é nula a transmitância através do so10. 
3. MATERIAL E METODOS

\subsection{Localização Geográfica}

A ārea estudada situa-se na Província Geomorfológica denominada "Depressão Periférica", entre as coorde-

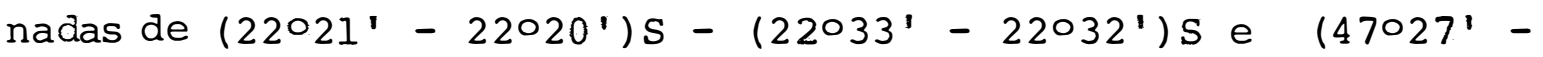

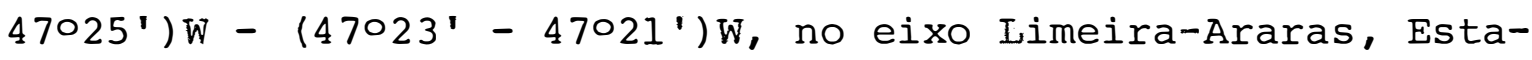
do de São Paulo. A área é representada por uma faixa de cobertura aerofotogramétrica e fotográfica multisensorial, executada pela NASA em 1969 (INPE, 1975), podendo ser visualizada na Figura 4.

\subsection{Geologia}

A Depressão Periférica compreende, conforme definição de ALMEIDA (1964), uma área sensivelmente rebaixada pela erosão, entre as terras altas do Planalto Atlântico e as cristas igualmente elevadas das cuestas basálticas, segundo a compartimentação geomorfológica do Estado de são Paulo.

o relevo regional é constituído por colinas de formas suavizadas, cuja declividade não ultrapassa 5\%, com vertentes longas, podendo ser classificado como suave ondu- 

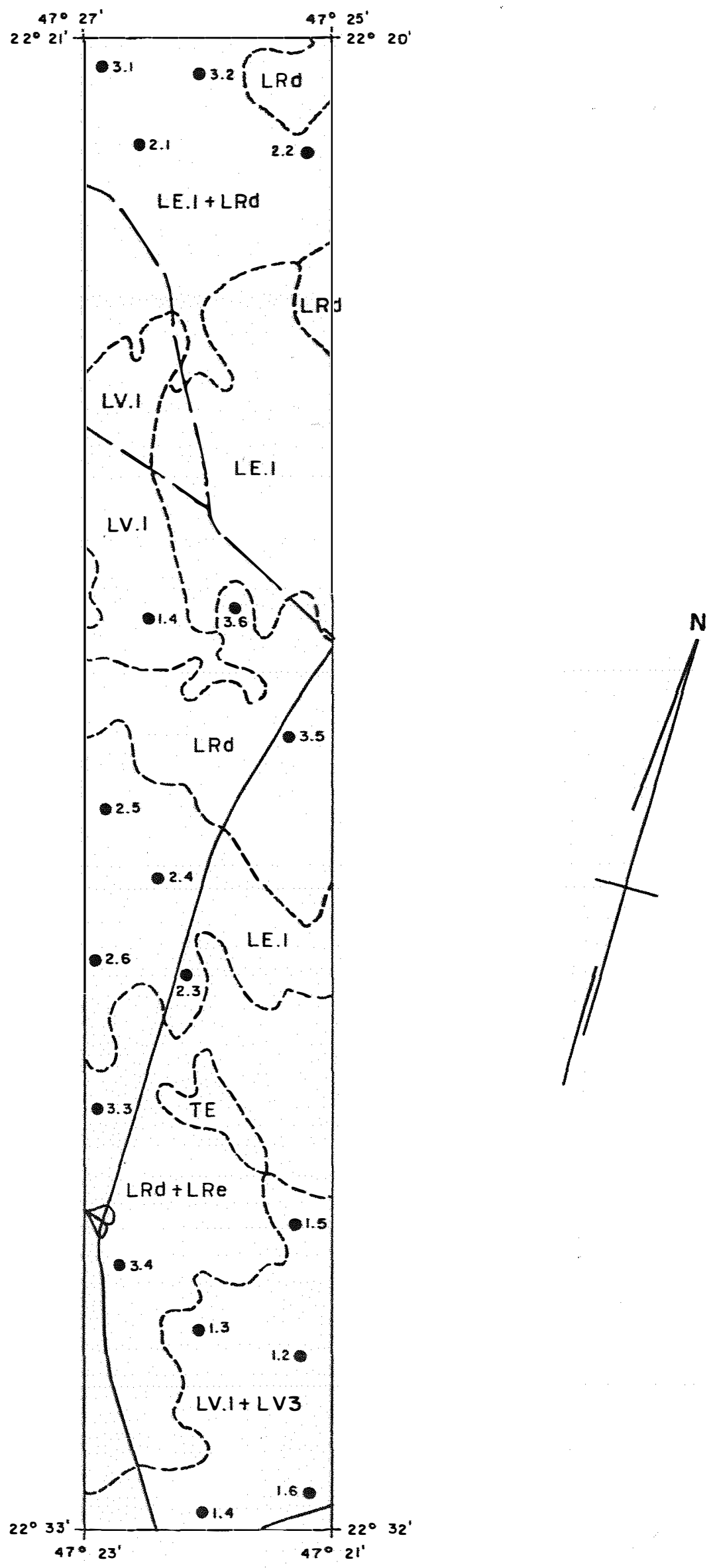

Fig. 4 - Localização da área estudada (unidades pedológicas e pon tos amostrados) (escala 1: 100.000) BRASIL/IBG (1969) e OLIVEIRA et alii (no prelo). 
lado ao longo de toda a ārea.

o quadro 3, resume a cronogeologia do substrato da área estudada. INSTITUTO GEOGRAFICO E GEOLOGICO (1974).

As rochas sedimentares relecionadas aos Grupos Tubarão e Passa-Dois, assim como as intrusivas básicas, ocupam a quase totalidade da área.

Capeando os sedimentos resultantes do intemperismo dessas rochas, nas cotas mais altas, ocorrem extensos depósitos argilosos de material remanejado e bastante intemperizado, descritos por OLIVEIRA et alii (1979). Esses depósitos representam a quase totalidade da área estudada, aos quais estão relacionados solos bastante profundos, porosos e de baixa fertilidade.

Conforme descrevem OLIVEIRA et alii (1979), entremeados ao assoalho cristalino e o manto de rochas sedimentares, ou mesmo infiltrados entre os sedimentos, ocorrem por vezes, sills, lacólitos e batólitos de diabásio que se relacionam às áreas mais salientes da paisagem e cujo material, exposto ao intemperismo, contribuiu de maneira significativa na formação dos solos circunvizinhos.

\subsection{Clima}

O clima da Região em que está localizada a área em estudo pode ser identificado, segundo o sistema kOppen, como sendo subtropical úmido, do tipo Cwa.

Segundo SETZER (1966), as características deste clima são: precepitação superior a $1.000 \mathrm{~mm}$ anuais e temperatura média inferior a $180^{\circ} \mathrm{C}$ no mes mais frio e superior a $22{ }^{\circ} \mathrm{C}$ no mes mais quente. 


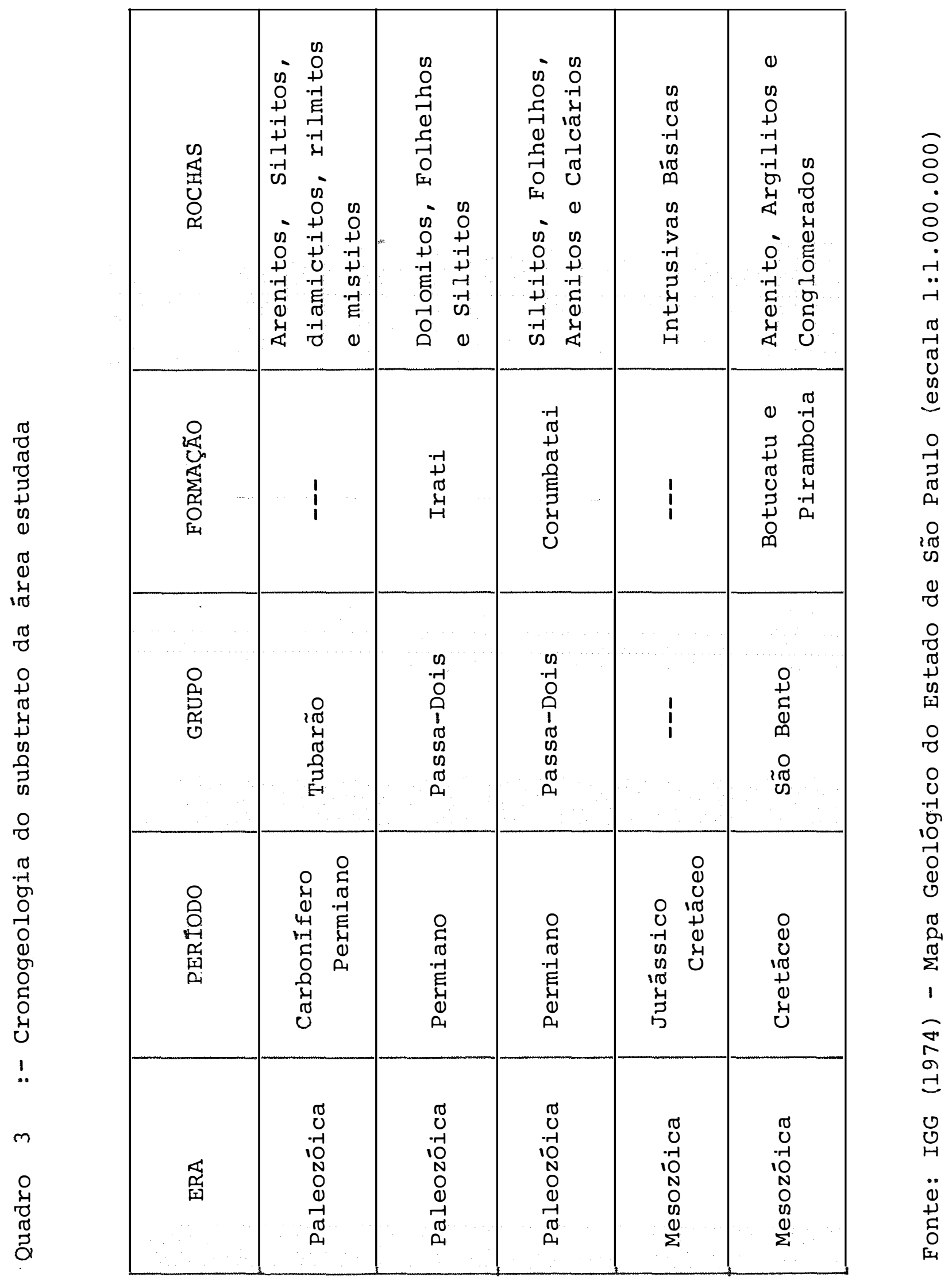




\subsection{Solos}

As unidades de solo, para as quais foram estabelecidos os valores de densidade ótica das imagens fotográficas, testando-se a significância dos mesmos na avaliação das diferenças quantitativas da cor e reflectāncia espectral relativa, são as seguintes:

a) LRd - Latossolo Roxo distrófico, A moderado, textura argilosa, relevo suave ondulado.

b) LE 1 - Latossolo Vermelho Escuro, Alico, A moderado, textura argilosa, relevo aplainado ou suave ondulado.

c) LV 1 - Latossolo Vermelho Amarelo, Alico, A moderado, textura argilosa, relevo aplainado ou suave ondulado.

As unidades citadas, são solos provenientes do retrabalhamento de sedimentos argilosos, argilitos e siltitos das formações Tubarão e Irati, assim como, provenientes do intemperismo e retrabalhamento de basaltos, ocorrendo dominantemente no eixo Limeira-Araras, no Estado de São Paulo, conforme ilustra a Fiqura 4.

As características das unidades pedológicas estudadas, que foram descritas por OLIVEIRA et alii (*), são as seguintes:

a) LRd - Unidade Barão Geraìdo

Classificação: Latossolo Roxo distrófico, A moderado, textura argilosa, relevo suave ondulado.

Caracteristicas Gerais: Compreende solos argilosos, espessos, friáveis e porosos. O horizonte B latossólico é

(*) OLIVEIRA, J.B. ; J.R.F. MENK; J.L. BARBIERI; C.L. ROTTA e W.A. TREMOCOLDI, Levantamento Pedológico Semi-detalhado. do Estado de São Paulo - Quadrícula de Araras. Campinas, Instituto Agronômico (não publicado). 
de cor bruno avermelhado escura ou vermelha muito escura, com elevados teores de ferro total, o qual pode ser estimado no campo, como característica diferencial, através do emprego de um imã, devido à elevada contribuição de magnetita.

são solos ácidos, com soma e saturação de bases baixas embora sejam baixos os teores de alumínio trocável. A altitude de ocorrência desses solos está entre 560 750 metros, com relevo suave ondulado constituido por colinas de vertentes longas, com topo abaulado e declives inferiores a 5\%.

O material de origem desses solos é resultante do intemperismo e retrabalhamento de basaltos.

b) LE 1 - Unidade Limeira

Classificação: Latossolo Vermelho Escuro, Alico, A moderado, textura argilosa, relevo aplainado ou suave ondulado.

Características Gerais: São solos profundos, bem drenados, porosos, com textura argilosa ao Iongo de todo o perfił. O horizonte B latossólico é friável, espesso, muito homogêneo, cuja cor pode chegar a 3,5 YR 3/5.

Esta unidade ocorre em relevo suave ondulado com vertentes longas e declividades inferiores a 5\%, com altitudes variando entre 580 - 740 metros.

o material de origem é constituido por sedimentos argilosos retrabalhados, provenientes do intemperismo de argilitos e siltitos das formações Tubarão e Irati. Esta unidade diferencia-se da anterior, Barão Geraldo, por apresentar menor quantidade de ferro total, além da cor do horizonte B normalmente mais clara, podendo entretanto, em alguns casos, ser idêntica à daquela unidade. 
c) LV 1 - Unidade Mato Dentro

Classificação: Latossolo Vermelho Amarelo, Alico, A moderado, textura argilosa, relevo aplainado ou suave ondulado.

Características Gerais: E constituída por solos profundos, bem drenados, porosos, com textura barrenta ou argilosa no horizonte $A$ e argilosa no horizonte $B$.

São solos muito ácidos, com valores muito baixos de soma e saturação de bases.

O relevo é aplainado a suave ondulado, com declives inferiores a 5\%, sendo que a altitude varia de 580 - 650 metros.

O material de origem resulta do retrabalhamento de materiais provenientes de sedimentos argilosos da Formação Tubarão.

Segundo OLIVEIRA et alii (1979), esta unidade se diferencia da anterior ( $\operatorname{LE} 1$ ) por apresentar coloração mais amarela que 3,5 YR.

Os solos descritos, quando examinados através de fotografias aéreas pancromáticas, não apresentam diferenças quanto aos aspectos da paisagem, no que diz respeito ao padrão de drenagem superficial ou características do relevo, como se pode notar pela homogeneidade das características descritas.

Uma pesquisa de critérios de fotointerpretação aplicada a solos da quadrícula de Campinas, anteriormente desenvolvida por DONZELI (*), envolvendo esses solos, além de outros, mostrou que não existem diferenças nas características quantitativas do padrão de drenaqem, para essas

(*) DONZELI, P.L., Critérios de Fotointerpretação aplicados à solos da Quadrícula de Campinas. Campinas Instituto Agronômico (não publicado). 
unidades, como se pode notar pelas Figuras 5 e 6 , que mostram as relações entre duas características do padrão de drenagem superficial. Essas características são a densidade de drenagem e a razão de textura ou frequência de calhas, aplicadas a solos por FRANÇA (1968). Pode-se notar a proximidade dos valores desses dois índices para as unidades LRd, LE 1 e LV 1, o que não ocorreu com as demais unidades estudadas.

\subsection{Material fotogräfico}

Foram utilizadas aerofotografias provenientes da missão 96, executada pela NASA em 1969, na Região de Campinas, Estado de são Paulo (INPE, 1975).

As características técnicas da cobertura aerofotográfica utilizada são as seguintes:

a) Transparências "Ektachrome" e Infravermelho Colorido

Altura de vôo $=7.500$ pés $(2.475 \mathrm{~m})$

Escala aproximada $=1: 16.000$

Recobrimento longitudinal de $60 \%$

Linha 4

Passagem 1

Data 1969

b) Transparências "Ektachrome" e Infravermelho Colorido

Altura de vôo $=3.000$ pés $(990 \mathrm{~m})$

Escala aproximada $=1: 6.000$

Recobrimento longitudinal de $60 \%$

Linha 4

Passagem 1

Data 1969

Para orientação dos trabalhos de campo foram utilizadas aerofotografias pancromāticas da cobertura aerofotogramétrica do Estado de são Paulo, executada pela VASP 


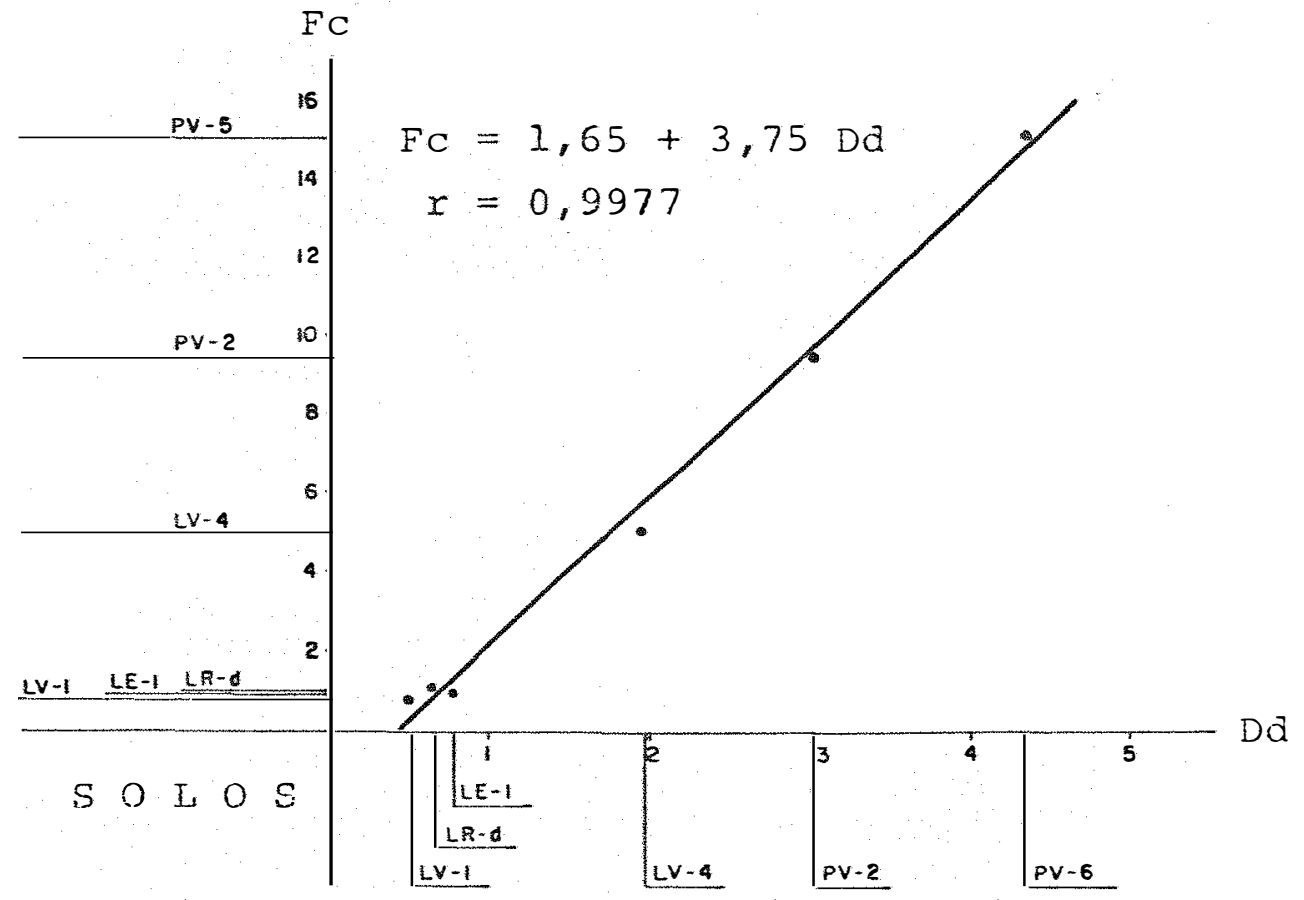

Fig. 5 Relacão funcional entre densidade de drenagen (Da) e Erequencia de calhas (FC) para as seis unidades de solo estudadas.

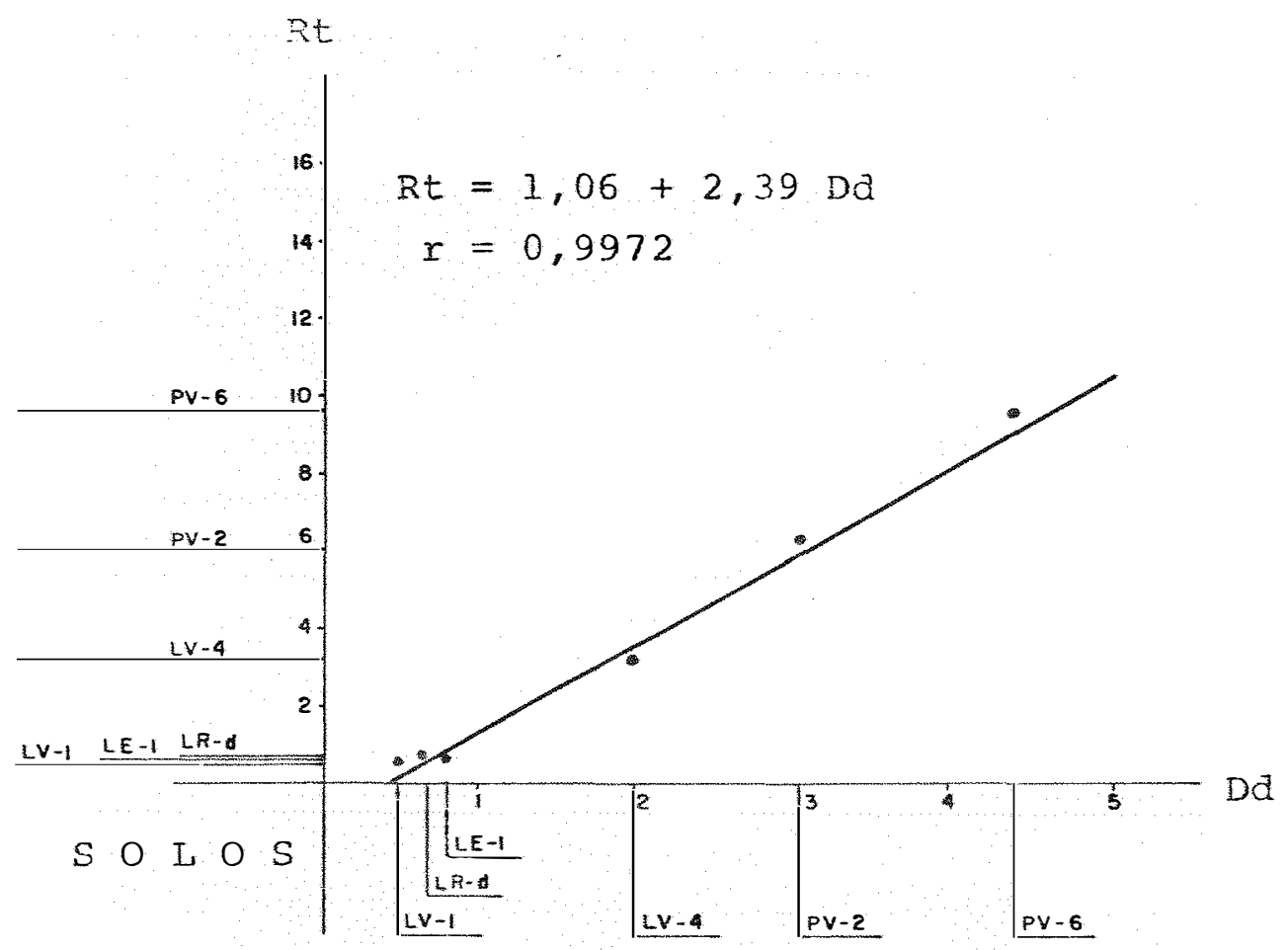

Fig.6 Relagão Eunclonal entre densidade de drenagem (Dd) e a razão de tertura ( $R t$ ) para as seis unizades de solo estudadas. 
para o Instituto Brasileiro do Café em 1971, em escala $1: 25.000$.

3.6. Equipamentos

3.6.1. Densitômetros

$\mathrm{Na}$ pesquisa foram utilizados densitômetros de reflexão Mac Beth TD 519, para leituras de densidade de cópias em papel e densitômetros de transmissão Mac Beth TD 504 para leituras de densidade em transparências fotográficas. Ambos os densitômetros foram utilizados para efetuar as leituras com quatro diferentes filtros, vermelho, verde, azul e visual.

Os filtros incluidos no densitômetro de reflexão são Wrattens 106W (visual), 25 (vermelho), 47 (azul) e 58 (verde). Os filtros incluidos no densitômetro de transmissão são Wrattens 106W (visual), 92 (vermelho), 93 (verde) e 94 (azul). Os densitômetros foram calibrados para produzir leituras comparáveis.

\subsubsection{Estereoscópios}

Para seleção das áreas a serem estudadas, utilizou-se estereoscópio Wild ST-4, com binoculares de $3 x$.

\subsection{Seleção das glebas de solo para estudo}

Através da análise estereoscópica detalhada das aerofotografias infravermelho colorido e "ektachrome" em escala aproximada 1:6.000, levando em consideração as técnicas propostas por MEYER (1969), procedeu-se à seleção das áreas ou glebas, em cujas imagens fotográficas ou amostras de solo foram efetuadas as medidas densitométricas.

O critério utilizado na seleção das glebas levou em consideração os fatores que pudessem influenciar nos registros tonais ou de cores e, consequentemente, as medidas 
de densidade ótica, com base na revisão da literatura.

3.7.1. Fatores que influenciaram as medidas densitométricas

Os principais fatores considerados como influenciadores dessas medidas são os seguintes:

a) Fatores Técnicos

Eliminadas as características comuns à cobertura aerofotográfica utilizada, ou sejam, características dos materiais ou equipamentos (filmes, filtros, etc.) e técnicas de exposição, citam-se os seguintes:

a.1) Técnicas de processamento

Essas técnicas, quando automáticas, poderão anular o efeito diferencial do registro da reflectância espectral dos solos que se deseja avaliar, ou então, quando manuais, acentuar diferencialmente densidades de imagens representativas de solos semelhantes.

a.2) Efeito de lentes "Vignetting"

E a ocorrência de maior iluminância próximo ao centro ótico, causada pela perda de luz nas bordas das lentes, que resulta um escurecimento nas bordas das fotografias. Geralmente esse efeito é corrigido com a utilização de um filtro anti-"vignetting".

b) Fatores do Terreno

Alguns fatores do terreno estranhos às características do solo que se deseja avaliar, podem influenciar as medidas de densidade ótica relativa. Entre eles, citam-se o ângulo de exposição e o tempo e técnicas de preparo do solo para plantio.

b.1) Ângulo de exposição

Esse fator é condicionado pela topografia,alterando o ângulo de reflexão da luz solar. No caso particu- 
lar desta pesquisa pode ser negligenciado, uma vez que a área em estudo possui topografia plana.

b.2) Tempo de preparo das glebas

A variação no tempo e técnicas de preparo das glebas para plantio da cana-de-açucar pode afetar significativamente a cor e a reflectância espectral do solo, tanto pelas diferenças no teor de umidade, como pela estruturação da camada superficial. Esta é considerada como a principal cau sa de variação das medidas de densidade de imagens representativas de solos da mesmå unidade.

c) Fatores Metereológicos

Embora se considere, neste particular, condições uniformes para a faixa de vôo estudada, algumas variações podem ocorrer ao longo da ārea em função da presença de nevoeiro, mormaço ou a ocorrência de precipitações localizadas.

\subsubsection{Métodos de seleção das glebas}

Com a finalidade de minimizar a influência dos fatores citados sobre o registro tonal, empregou-se o seguinte método para seleção das áreas:

Utilização de fotografias infravermelho em escala grande (1:6.000), com a possibilidade de se detectar qualquer cobertura vegetal viva ou morta sobre o terreno, com uma visão de detalhes da superfície, possibilitando e escotha das glebas preparadas para plantio, com a maior homogeneidade possível.

As áreas foram selecionadas sempre dentro do campo de visão estereoscópica, aproveitando-se apenas a área situada entre o ponto principal e a metade do recobrimento longitudinal de cada aerofoto. Com esse procedimento, julga-se ter fixado dentro de limites considerados aceitáveis 
grande parte dos fatores causadores de êrro nas determinações. Na seleção prévia das glebas foi ainda levada em consideração a rede de pontos de prospecção do levantamento de reconhecimento semi-detalhado da Região.

Foram selecionadas seis glebas para cada unidade de solo, com tamanho variável de 1,0 a 3,0 ha, em locais previamente amostrados por OLIVEIRA et alii (1979), Figura 4.

Dentro das glebas selecionadas foram coletadas amostras do horizonte superficial $(0-20 \mathrm{~cm})$ para análise densitométrica da cor.

\subsection{Preparo das amostras de solo para análise densitomé- $\underline{\text { trica }}$}

No preparo das amostras de solo para análise densitométrica, procurou-se apoio na literatura existente, principalmente em trabalhos similares realizados para análise espectrofotométrica da cor.

Como é grande a influência do tamanho dos agregados do solo na reflexão da luz pela amostra, procurou- se seguir a recomendação de MONTGOMERY et alii (1976), padronizando a amostra em peneira com malha de $1 \mathrm{~mm}$ de diâmetro.

SHIELDS et alii (1968) ressaltam a influência da utilização de placa de vidro sobre a amostra, na obtenção dos valores de reflectância espectral de solos com o emprego de espectrofotômetros. No entanto, constatou-se que esse procedimento seria inevitável no caso de utilização de densitômetros de reflexão, por razões técnicas de adaptação de metodologia, para essa finalidade, evitando-se o contato direto das partículas de solo com as partes sensoras externas do aparelho. 
Tomou-se duas placas de acrílico com dimensoes de $15 \mathrm{~cm}$ por $25 \mathrm{~cm}$ e com 0,3 cm de espessura, onde foram perfurados 18 orifícios de $1,2 \mathrm{~cm}$ de diâmetro em cada uma, conforme ilustra a Figura 7 .

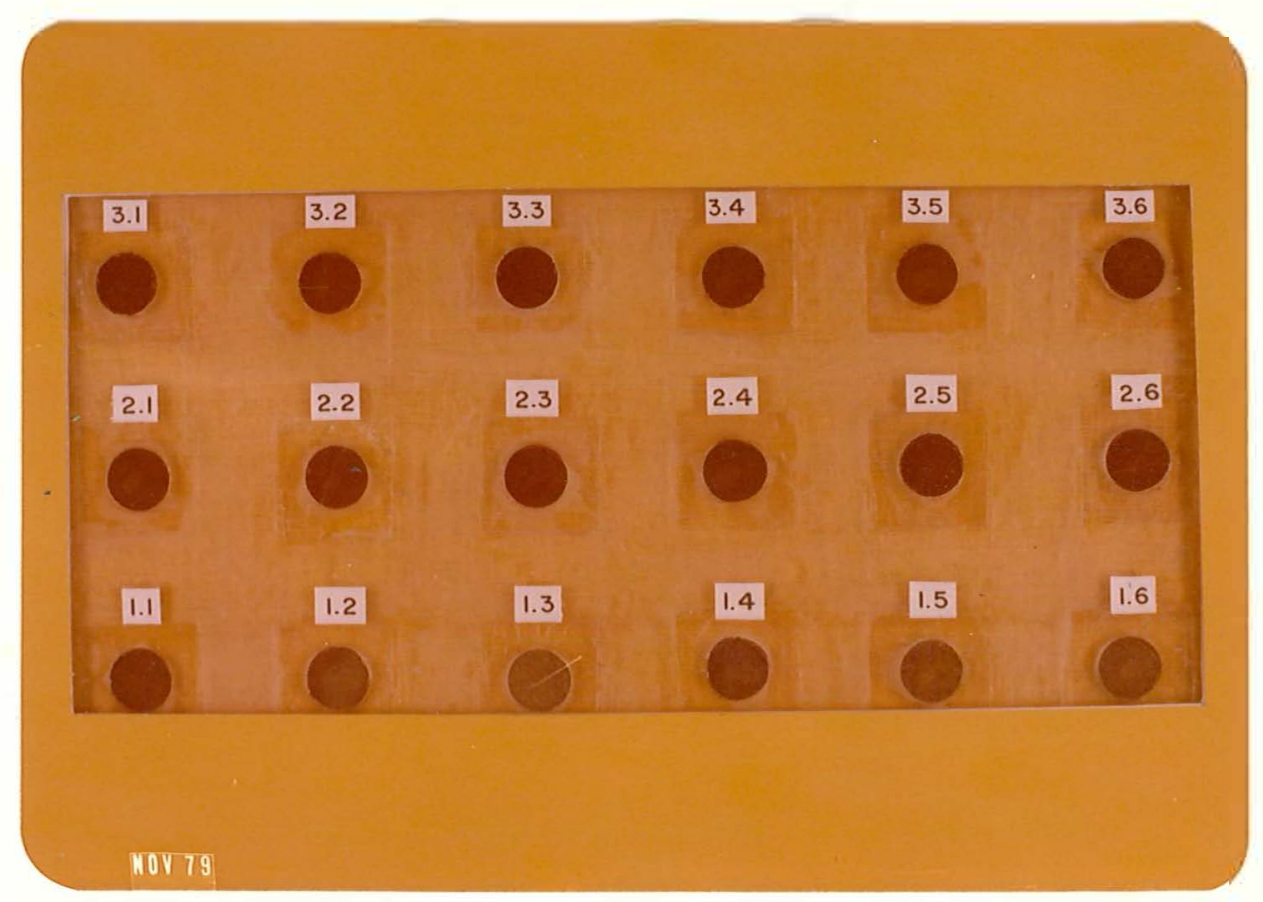

Figura 7. Disposição das amostras de solo para análise densitométrica

Os orifícios foram vedados de um dos lados com lamínulas de microscópio de $24 \mathrm{~mm}$ x $24 \mathrm{~mm}$, com utilização de uma cola especial. As amostras de T.F.S.A. (Terra Fina Seca ao $\mathrm{Ar}$ ), padronizadas em peneira de $1 \mathrm{~mm}$, foram colocadas nos orifícios. As amostras numeradas de una das placas foram umedecidas com quantidades iguais de água (3 gôtas). Após essa operação, os orifícios foram vedados em ambas as placas com laminulas idênticas às primeiras, ficando as amostras ligeiramente comprimidas. 


\subsection{Anālise densitométrica}

Após a seleção das glebas, efetuou-se a medição da respectiva densidade ótica das imagens homólogas em transparências "Ektachrome" e Infravermelho Colorido, em escala aproximada 1:16.000. Para essa operação utilizou-se densitômetro de transmissão Mac Beth TD 504, obtendo-se valores médios de três repetições em quatro filtros, em diferentes locais da imagem.

Com o emprego de densitômetro de reflexão Mac Beth TD 519, foram também obtidas as leituras de densidade ótica sobre as correspondentes amostras de solo, obtenđo-se a média de três repetições em locais diferentes da amostra. Com esse procedimento, foram obtidas leituras de densidade ótica de amostras secas (TFSA) e umedecidas, com os filtros vermelho, verde, azul e visual.

\subsection{Determinação das cores Munsell/densitométricas}

Com base nas leituras densitométricas obtidas e seguindo a metodologia proposta por RIB (1968), foram estabelecidas as cores Munsell/densitométricas para as amostras de solo secas e umedecidas das glebas representativas dos solos estudados, em transparências "ektachrome" e infravermelho colorido.

Conforme a metodologia adotada, foram estabelecidos os valores $\mathrm{R}, \mathrm{RR}$ e RRR, cada um deles constituindo uma das variáveis das equações de regressão, para estabelecimento respectivamente do valor, matiz e croma Munsell/densitométricos.

Considerando:

$\mathrm{R}$ = Variável geradora do "valor"

$\mathrm{RR}$ = Variável geradora do "matiz" 


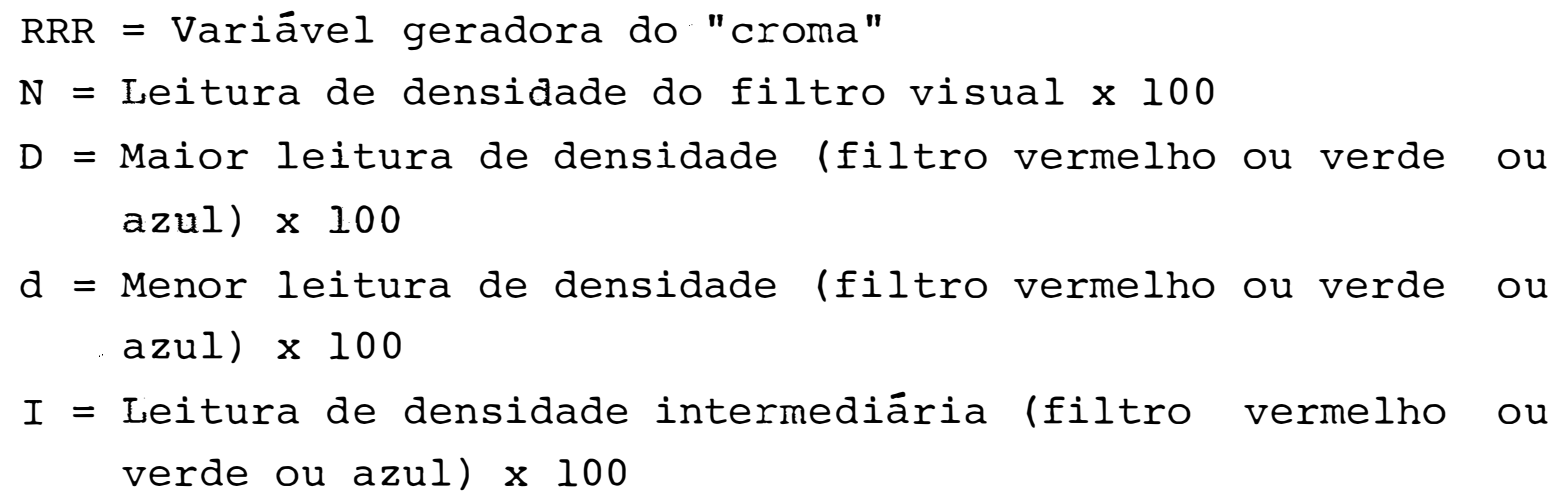

O "valor" Munsell/densitométrico foi estabelecido pela seguinte equação de regressão:

$$
V=14,95-2,32 \sqrt[3]{R}
$$

Os valores D, d, A, B entraram no ábaco da Figura 2 para seleção da curva para estabelecimento do "matiz" Munsell/densitométrico.

Os valores RRR e V entraram no ábaco da Figura 3 para estabelecimento do "croma" Munsell/densitométrico.

Em todos os valores calculados graficamente, utilizou-se um compasso de escala. 


\subsection{Análise estatistica}

Os valores de densidade ótica espectral da imagem e das cores Munsell/densitométricas para cada unidade de solo, foram comparadas estatísticamente através do teste não paramétrico de Kruskal-wallis.

Segundo CAMPOS (1979), devido às exigências do modelo matemático dos delineamentos estatisticos no campo paramétrico, (normalidade dos dados, homogeneidade das variâncias de tratamentos, etc.), os testes competidores deste no campo paramétrico são mais eficientes, permitindo conclusões mais acuradas. No entanto, a grande versatilidade e simplicidade deste teste, o tornam recomendado, em um caso como o do presente trabalho, como substituto do teste $F$, na análise de um ensaio não inteiramente casualizado.

No caso presente, a finalidade da aplicação do teste é averiguar se as 18 amostras independentes são provenientes de uma mesma população (unidade de solo) ou provêm de populações distintas. Admitindo-se três tratamentos ( 3 unidades de solo), o teste permite averiguar se há diferença entre pelo menos dois deles.

Kruskal e Wallis, citados por CAMPOS (1979), apresentam pressuposições gerais a respeito do tipo de distribuição das observações, ou sejam:

a) As observações são todas independentes.

b) Dentro de uma dada amostra, todas as observações são provenientes da mesma população.

c) As populações são aproximadamente da mesma forma e continuas. 
Assim, duas hipóteses são formuladas:

19) $\mathrm{H}_{\mathrm{O}}: \mathrm{t}_{1}=t_{2}=\ldots=t_{\mathrm{k}}$

onde $k=3$ (tratamentos)

29) $\mathrm{H}_{\mathrm{a}}$ : Pelo menos dois tratamentos (unidades de solo) diferem entre si.

Quando $\mathrm{H}_{\mathrm{O}}$ é rejeitado, isto é, pelo menos dois tratamentos apresentam diferenças entre si, detectadas pelo teste a um nível de significância de até 5\%, empregam-se as "Comparações Múltiplas", que podem ser consideradas como uma complementação do teste de Kruskal-Wallis, para verificar quais tratamentos diferem entre si e a que nível de significância.

Também para esse caso observa-se as considerações de CAMPOS (1979) sobre a menor eficiência dos processos não paramétricos empregados nas comparações múltiplas do que seus concorrentes do campo paramétrico.

No entanto, seguindo a recomendação verbal desse autor, procedeu-se também à análise de variância com os dados de densitometria observando a inexistência de diferenças entre a significância de $F$ e a significância de $H$, no teste de Kruskal-Wallis.

Por esse motivo, optou-se pela apresentação das correlações entre os valores densitométricos, utilizando as correlações de Pearson no campo paramétrico, ao invés dos testes de Kendall ou Spearman do campo não paramétrico. 


\section{RESULTADOS E DISCUSSÃO}

Os resultados das medições de densidade ótica das amostras de solo e suas respectivas imagens fotogrāficas, encontram-se nos quadros $4,5,6$ e 7 . Nesses quadros são apresentadas tambēm as médias e o desvio padrão para as três unidades de solo estudadas, com leituras efetuadas nos filtros vermelho, verde, azul e visual. As leituras de densidade D apresentadas foram multiplicadas pelo valor 100 , conforme RIB (1968), constituindo a base dos cálculos da cor Munsell/densitométrica.

Para facilitar a interpretação estatística dos resultados da matiz Munsell/densitométrica, esta foi tambēm representada nos Quadros 8 e 9, pelo número da matiz de Munsell, variando do valor zero a dez no matiz " $R$ ", passando pelos matizes intermediários "YR", "Y", "GY", "BG", "B", "PB", "P", acrescentando o valor 10 para cada um deles, até atingir o valor 100 no matiz "RP". (Vide Figura 2, RIB, 1968).

\subsection{Interpretação dos valores de densidade ótica de ban- das espectrais}

As leituras foram efetuadas em quatro dife- 


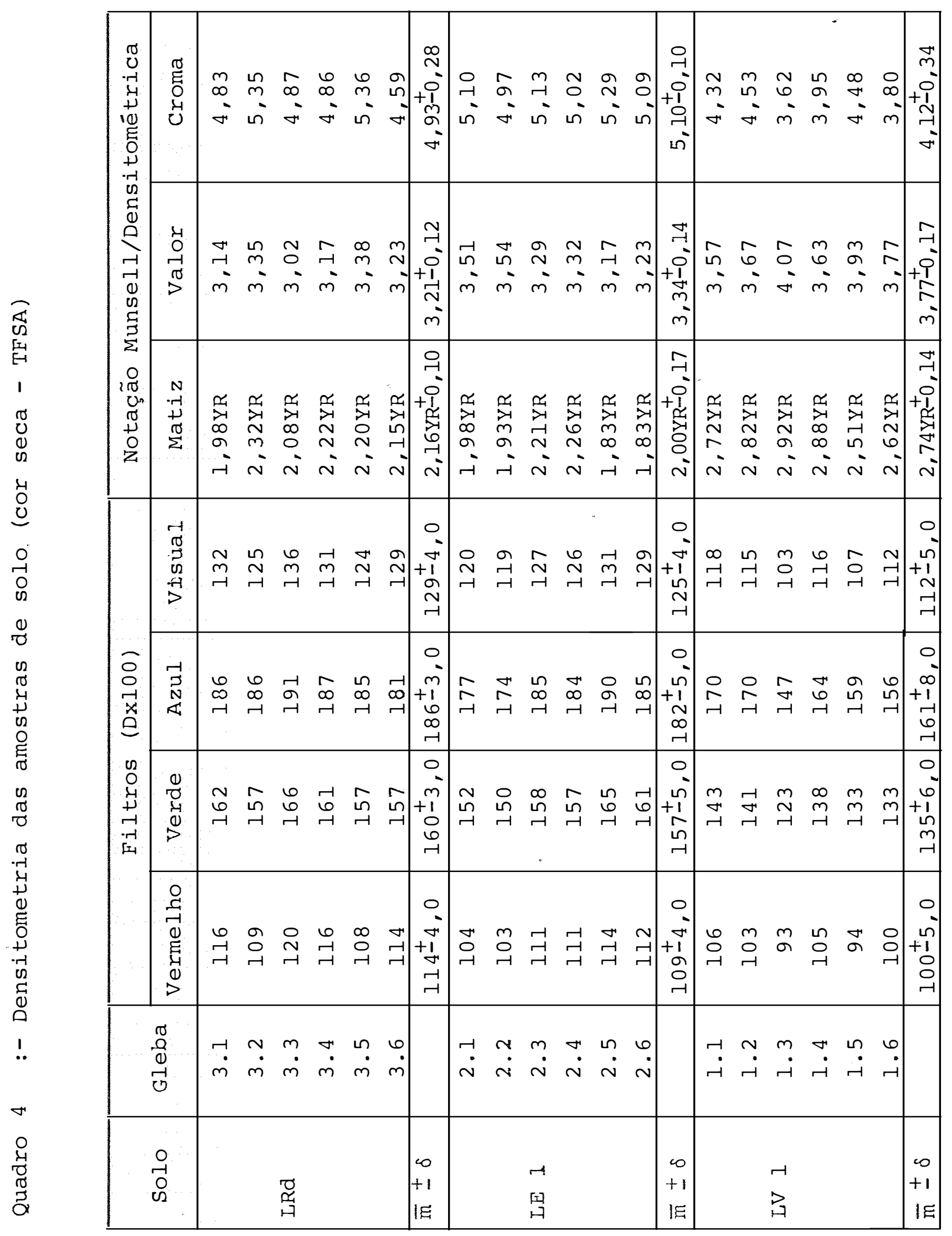




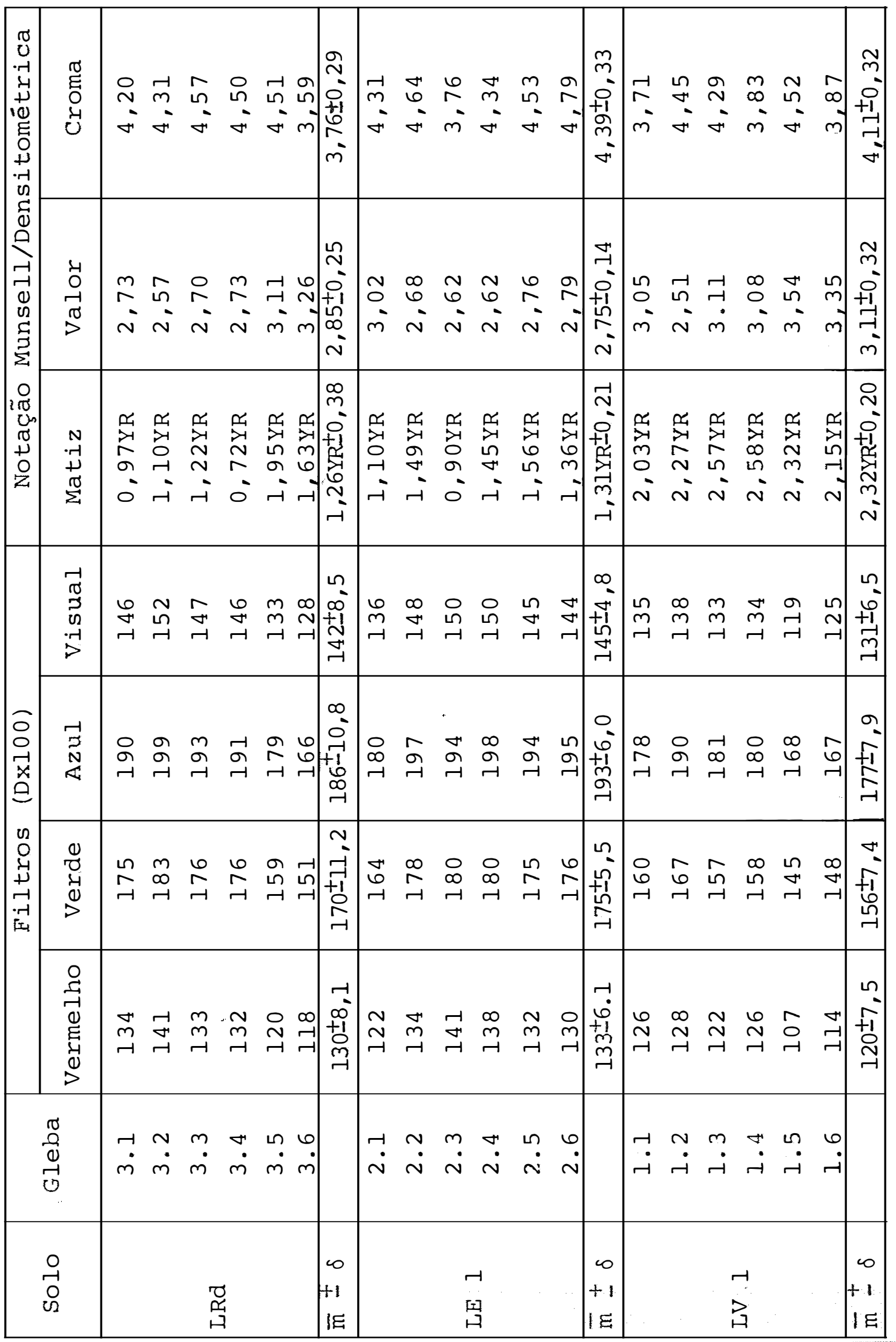




\begin{tabular}{|c|c|c|c|c|c|c|c|}
\hline 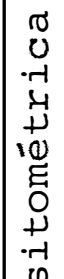 & $\begin{array}{l}\text { Oू } \\
\text { Oे } \\
\text { U }\end{array}$ & 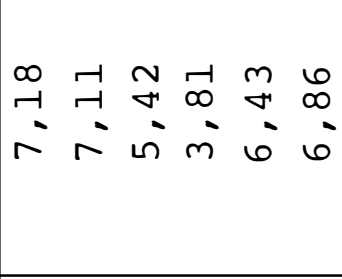 & & 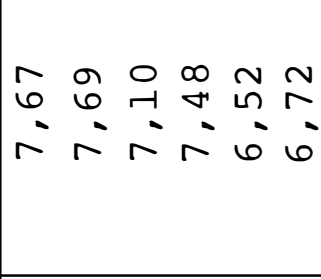 & 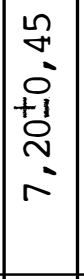 & 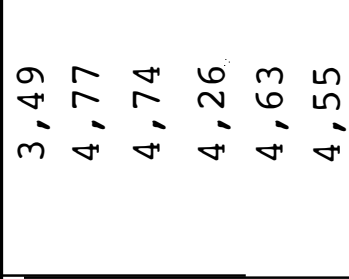 & 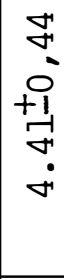 \\
\hline 是 & $\begin{array}{l}4 \\
0 \\
\stackrel{-1}{r} \\
>\end{array}$ & 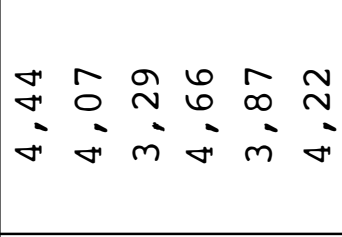 & 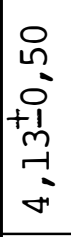 & 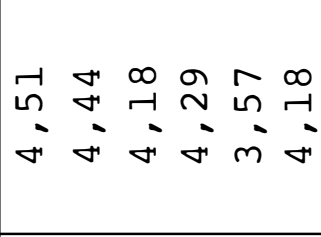 & $\begin{array}{c}\circ \\
\text { m } \\
0 \\
+1 \\
\text { न } \\
\text { न } \\
\dot{\sigma}\end{array}$ & $\mid \begin{array}{llllll}N & n & N & 0 & n & N \\
\text { in } & \text { in } & \text { in } & 0 & \text { in } & \text { in }\end{array}$ & in \\
\hline $\mid \begin{array}{c}0 \\
i \pi \\
0.0 \\
0 \\
0 \\
1 \\
0 \\
z\end{array}$ & 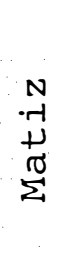 & 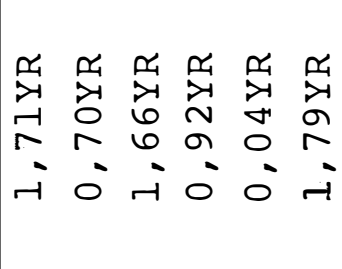 & 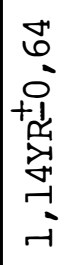 & 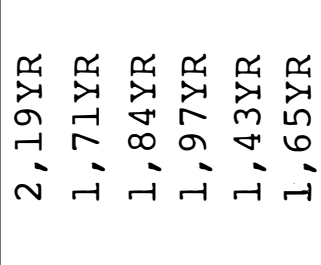 & 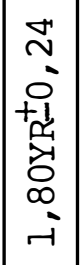 & 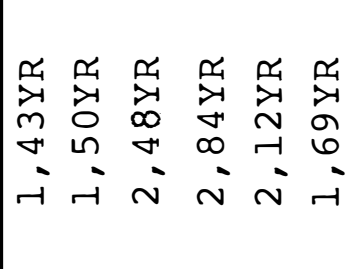 & 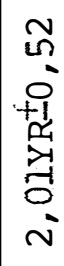 \\
\hline \multirow{4}{*}{ 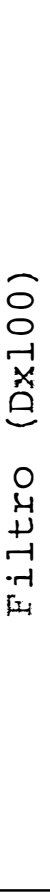 } & 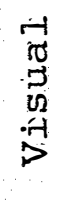 & 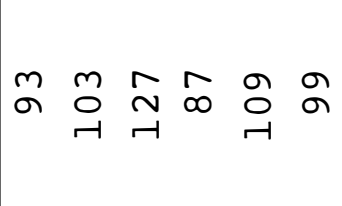 & $\begin{array}{r}\infty \\
\sim \\
\sim \\
+1 \\
+1 \\
0 \\
0 \\
-1\end{array}$ & 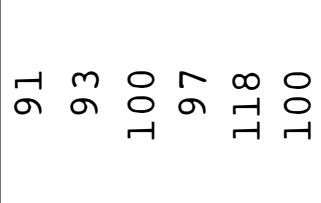 & $\begin{array}{r}m \\
\infty \\
+1 \\
8 \\
0 \\
-1\end{array}$ & $\begin{array}{llllll}n & 6 & -1 & 0 & n & m \\
6 & 6 & 6 & 1 & r & 6\end{array}$ & 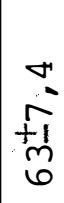 \\
\hline & 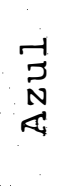 & 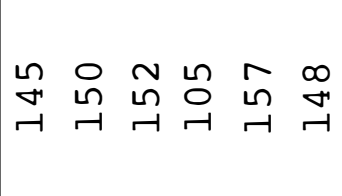 & $\begin{array}{r}\infty \\
0 \\
+ \\
+1 \\
-1 \\
ت \\
ت\end{array}$ & 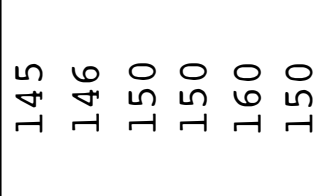 & $\begin{array}{r}\infty \\
-1 \\
+1 \\
0 \\
1 \\
1 \\
1\end{array}$ & 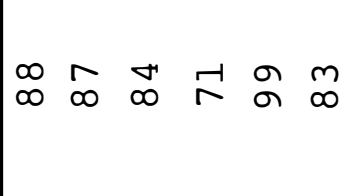 & $\begin{array}{l}N \\
\infty \\
+1 \\
\infty \\
\infty \\
\infty\end{array}$ \\
\hline & $\begin{array}{l}0 \\
\text { ¿े } \\
0 \\
0\end{array}$ & 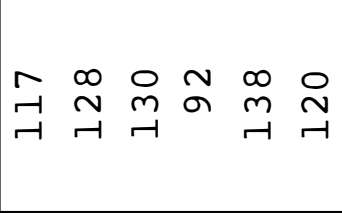 & 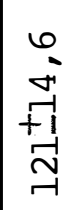 & 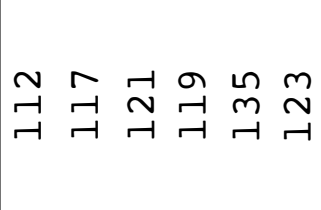 & $\begin{array}{c}0 \\
-1 \\
+1 \\
\sim \\
\sim \\
\sim \\
-1\end{array}$ & $\hat{r}$ & - \\
\hline & 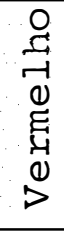 & 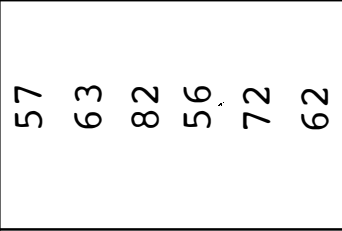 & $\begin{array}{l}+1 \\
+1 \\
\text { in } \\
\text { in }\end{array}$ & 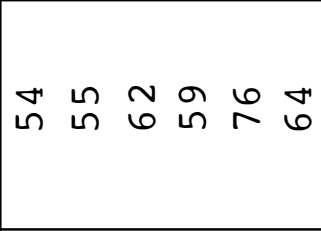 & $\begin{array}{c}m \\
r \\
+1 \\
\text { No }\end{array}$ & 䒽 & $\begin{array}{c}\infty \\
\substack{++1 \\
+}\end{array}$ \\
\hline & (j) & 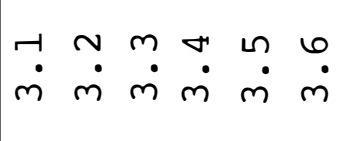 & & $\begin{array}{llllll}\dot{ } & \sim & m & \nabla & \sim & 0 \\
\dot{\sim} & \dot{\sim} & \dot{\sim} & \dot{\sim} & \dot{\sim} & \dot{\sim}\end{array}$ & & $\begin{array}{cccccc}- & \sim & m & \nabla & \sim & 0 \\
\dot{-} & \dot{-} & \dot{-} & \dot{-} & \dot{-} & \dot{-}\end{array}$ & \\
\hline \multicolumn{2}{|c|}{ 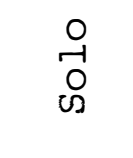 } & 古 & $\begin{array}{c}\infty \\
+1 \\
1 द\end{array}$ & 㞰 & $\begin{array}{c}\infty \\
+1 \\
1 E\end{array}$ & 学 & $\begin{array}{l}\infty \\
+1 \\
1 E\end{array}$ \\
\hline
\end{tabular}




\begin{tabular}{|c|c|c|c|c|c|c|c|c|c|c|c|c|c|c|c|c|c|}
\hline 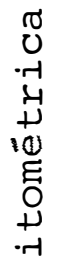 & 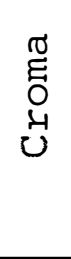 & 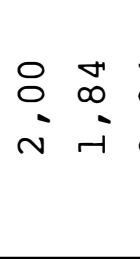 & à & $\hat{0}$ & 닫 & 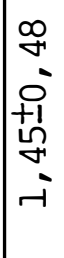 & $\stackrel{\ddot{N}}{\sim}$ & $\begin{array}{ll}\infty & 0 \\
r & c \\
\sim & 0\end{array}$ & $\begin{array}{l}a \\
0 \\
\text { i }\end{array}$ & 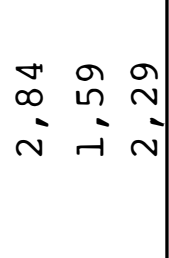 & $\begin{array}{l}0 \\
0 \\
0 \\
+1 \\
0 \\
\vdots \\
i\end{array}$ & $\begin{array}{ll}N & N \\
\text { in } & \text { in } \\
\text { i } & \text { n }\end{array}$ & $\stackrel{\infty}{m}$ & $\begin{array}{ll}6 & \infty \\
a & 0 \\
& m\end{array}$ & $\begin{array}{l}0 \\
0 \\
0 \\
i\end{array}$ & $\begin{array}{l}-1 \\
\infty \\
-1\end{array}$ & $\begin{array}{l}\text { ñ } \\
0 \\
+1 \\
\text { + } \\
\text { i }\end{array}$ \\
\hline 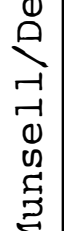 & $\begin{array}{l}4 \\
0 \\
-1 \\
0 \\
>\end{array}$ & $\begin{array}{ll}n & n \\
\sigma & m \\
& \sim\end{array}$ & r. & $\vec{r}$ & 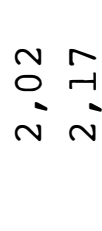 & 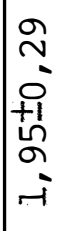 & $\begin{array}{l}\infty \\
0 \\
\sim\end{array}$ & $\begin{array}{ll}\infty & 5 \\
0 & \\
\sim & \end{array}$ & \begin{tabular}{l}
$m$ \\
\multirow{2}{*}{} \\
$i$
\end{tabular} & $\begin{array}{lll}m & n & r \\
N & \infty & n \\
N & -1 & N\end{array}$ & $\left|\begin{array}{c}0 \\
n \\
0 \\
+1 \\
0 \\
0 \\
\vdots \\
\vdots\end{array}\right|$ & $\begin{array}{lc}\infty & \text { r } \\
0 & 7 \\
\text { in } & \text { in }\end{array}$ & in & in & ? & $\begin{array}{l}\Delta \\
\vec{A} \\
\dot{A}\end{array}$ & $\begin{array}{l}\text { nn } \\
0 \\
+1 \\
+1 \\
0 \\
\text { in }\end{array}$ \\
\hline $\begin{array}{l}10 \\
0 \\
0 \\
0 \\
+0 \\
0 \\
z\end{array}$ & $\begin{array}{c}N \\
-1 \\
+\infty \\
\sum\end{array}$ & 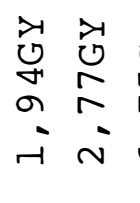 & 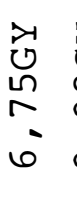 & $\begin{array}{l}\text { ry } \\
0 \\
\infty \\
\text { a } \\
\text { a }\end{array}$ & 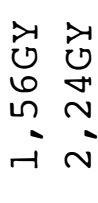 & $\begin{array}{l}\text { ỹ } \\
0 \\
0 \\
\text { N } \\
\dot{\sigma}\end{array}$ & $\begin{array}{l}71 \\
0 \\
m \\
0 \\
\text { N }\end{array}$ & 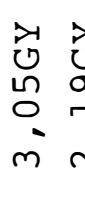 & $\begin{array}{l}\text { त्र } \\
0 \\
2 \\
\text { - } \\
\text { N }\end{array}$ & 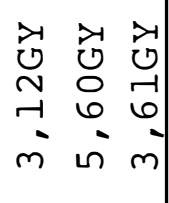 & 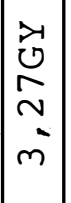 & \begin{tabular}{ll} 
r & \multicolumn{1}{c}{} \\
0 & \\
0 & 0 \\
a & in
\end{tabular} & $\begin{array}{l}\stackrel{a}{N} \\
\stackrel{1}{m}\end{array}$ & 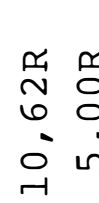 & 出 & 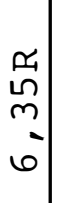 & $\begin{array}{l}\frac{1}{m} \\
m \\
0 \\
0\end{array}$ \\
\hline & 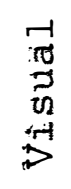 & $\begin{array}{ll}ન & 0 \\
6 & 0 \\
-1 & -1\end{array}$ & $\begin{array}{ll}6 & \\
\infty & \\
-1 & \end{array}$ & $\begin{array}{l}0 \\
\text { aे } \\
\end{array}$ & 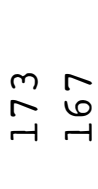 & 唄 & $\underset{\sim}{\infty}$ & \begin{tabular}{ll}
$\infty$ & 1 \\
\multirow{r}{r}{} & $u$ \\
& $r$
\end{tabular} & ñ & 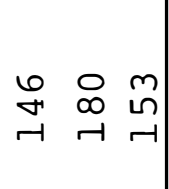 & 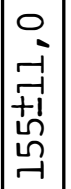 & $r \stackrel{r}{r}$ & $\underset{6}{6}$ & ชै वे & & $\begin{array}{l}-1 \\
0 \\
-1\end{array}$ & $\begin{array}{c}0 \\
m \\
+1 \\
+1 \\
\infty\end{array}$ \\
\hline $\begin{array}{l}0 \\
\circ \\
\circ \\
-1\end{array}$ & 永 & $\underset{r}{\stackrel{0}{r}} \stackrel{-1}{r}$ & $\begin{array}{c}\infty \\
\infty \\
-1 \\
r\end{array}$ & $\begin{array}{l}6 \\
\infty \\
-1\end{array}$ & 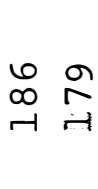 & $\begin{array}{l}0 \\
\text { in } \\
+1 \\
0 \\
0 \\
-1\end{array}$ & $\frac{0}{r}$ & $\begin{array}{ll}\infty & 1 \\
0 & ? \\
r & ?\end{array}$ & $\frac{6}{r}$ & $\begin{array}{lll}m & \infty & N \\
& \infty & \tilde{ન} \\
& & \end{array}$ & 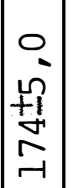 & $\begin{array}{cc}\hat{\infty} & m \\
\infty & \infty\end{array}$ & శิ & $\stackrel{m}{r} \approx$ & $\begin{array}{ll}0 \\
D \\
-1\end{array}$ & $\begin{array}{l}6 \\
\circ \\
-1\end{array}$ & $\begin{array}{l}0 \\
\dot{j} \\
+1 \\
+\infty \\
\infty\end{array}$ \\
\hline $\begin{array}{l}0 \\
0 \\
0 \\
0 \\
y \\
\\
\end{array}$ & 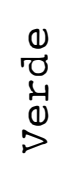 & 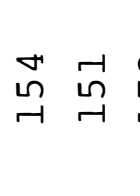 & $\begin{array}{l:}N \\
\end{array}$ & $\frac{a}{\pi}$ & $\begin{array}{ll}9 & 0 \\
6 & 0 \\
-1 & -1\end{array}$ & $\begin{array}{l}0 \\
0 \\
0 \\
+1 \\
+1 \\
0 \\
0 \\
-1\end{array}$ & $\underset{\pi}{\pi}$ & 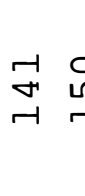 & $\begin{array}{l}\text { 온 } \\
\text { 남 }\end{array}$ & 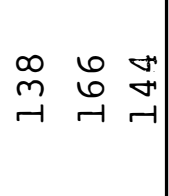 & $\begin{array}{c}0 \\
0 \\
\infty \\
+1 \\
0 \\
\infty \\
-1\end{array}$ & $\underset{\infty}{\infty}$ & $\vec{r}$ & 68 & $b_{-1}^{2}$ & $\begin{array}{l}\overrightarrow{1} \\
\circ \\
-1\end{array}$ & $\underset{\infty}{+\infty}$ \\
\hline$[x$ & 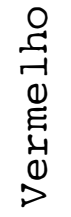 & $\begin{array}{ll}n & n \\
\text { nn } & \text { ñ }\end{array}$ & $\begin{array}{ll}\circ & 1 \\
\infty & 1 \\
-1 & \end{array}$ & $\begin{array}{l}\infty \\
\infty \\
\infty \\
-1\end{array}$ & $\begin{array}{ll}-1 & m \\
& 0 \\
-1\end{array}$ & 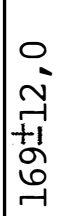 & $\begin{array}{l}6 \\
+ \\
-1\end{array}$ & $\underset{+}{\stackrel{5}{r}}$ & ñ & $\begin{array}{lll}0 & \infty & N \\
\sigma & \sim & n \\
-1 & -1 & -1\end{array}$ & $\begin{array}{c}0 \\
0 \\
\sim \\
+1 \\
+1 \\
m \\
n \\
-1\end{array}$ & નુ & $\stackrel{r}{\sigma}$ & $\stackrel{\sim}{\sigma}$ & & $\begin{array}{l}6 \\
\infty\end{array}$ & $\begin{array}{l}0 \\
\dot{m} \\
+1 \\
0 \\
0\end{array}$ \\
\hline & 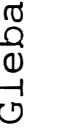 & $\begin{array}{ll}r & \stackrel{v}{m} \\
\dot{m}\end{array}$ & $\begin{array}{l}m \\
\dot{m},\end{array}$ & $\dot{m}$ & $\begin{array}{l}n \\
\dot{m}\end{array}$ & & $\dot{r}$ & $\begin{array}{ll}\sim & r \\
\sim & r\end{array}$ & $\begin{array}{l}m \\
\dot{v}\end{array}$ & $\begin{array}{lll}\forall & n & 0 \\
\dot{\sim} & \dot{\sim} & \dot{v}\end{array}$ & & $\begin{array}{r}-\dot{r} \\
\dot{-1}\end{array}$ & $\dot{m}$ & $\begin{array}{ll}\sigma & n \\
-1 & -\end{array}$ & ? & $\begin{array}{l}6 \\
-1\end{array}$ & \\
\hline & $\begin{array}{l}0 \\
0 \\
0 \\
0\end{array}$ & \multicolumn{4}{|c|}{ 总 } & $\begin{array}{c}\infty \\
+1 \\
15\end{array}$ & \multicolumn{4}{|c|}{ 年 } & $\mid \begin{array}{c}\infty \\
+1 \\
1 E\end{array}$ & \multicolumn{5}{|c|}{$\begin{array}{l}-1 \\
\text { 号 }\end{array}$} & $\begin{array}{l}\infty \\
+1 \\
1 E\end{array}$ \\
\hline
\end{tabular}




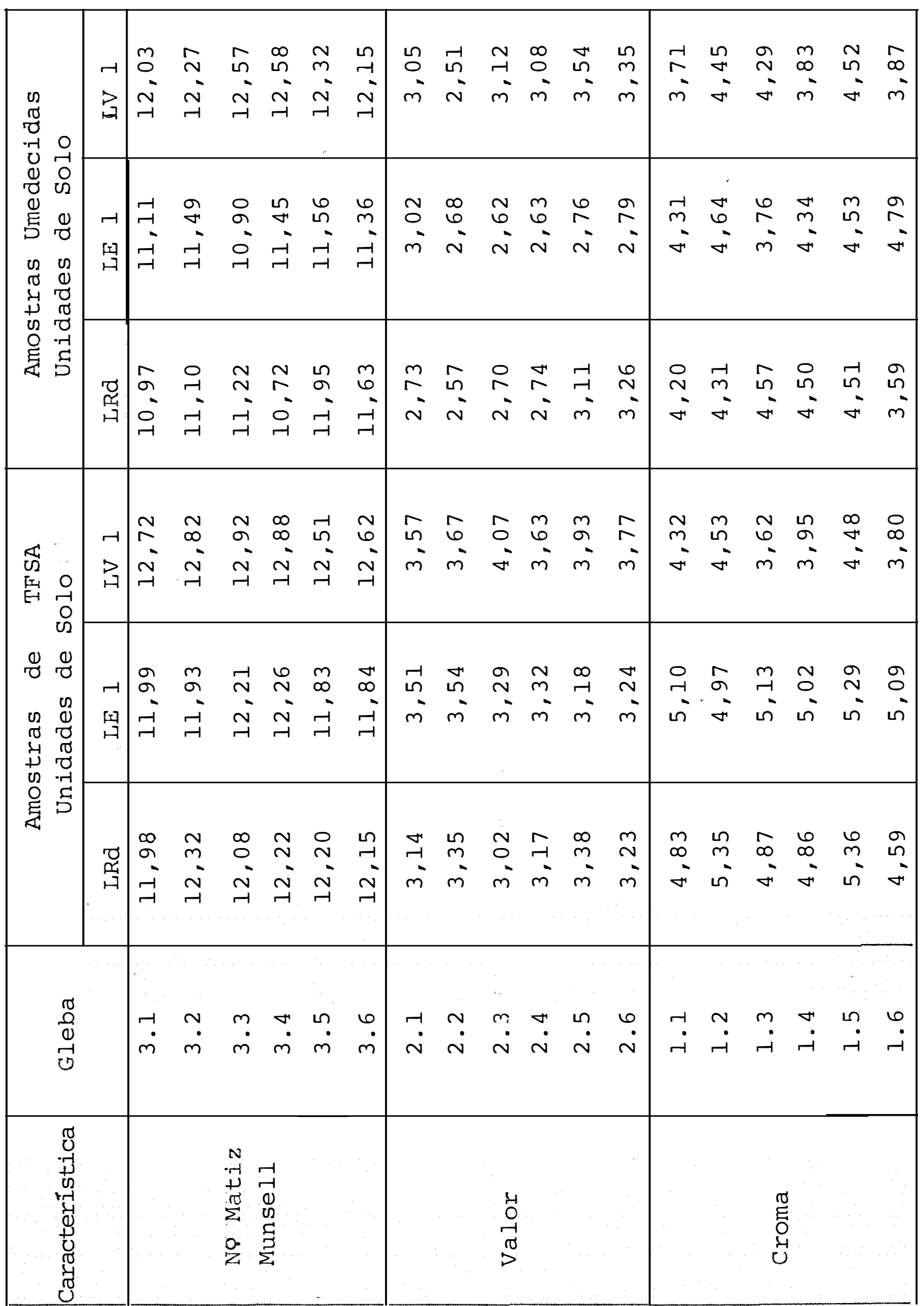




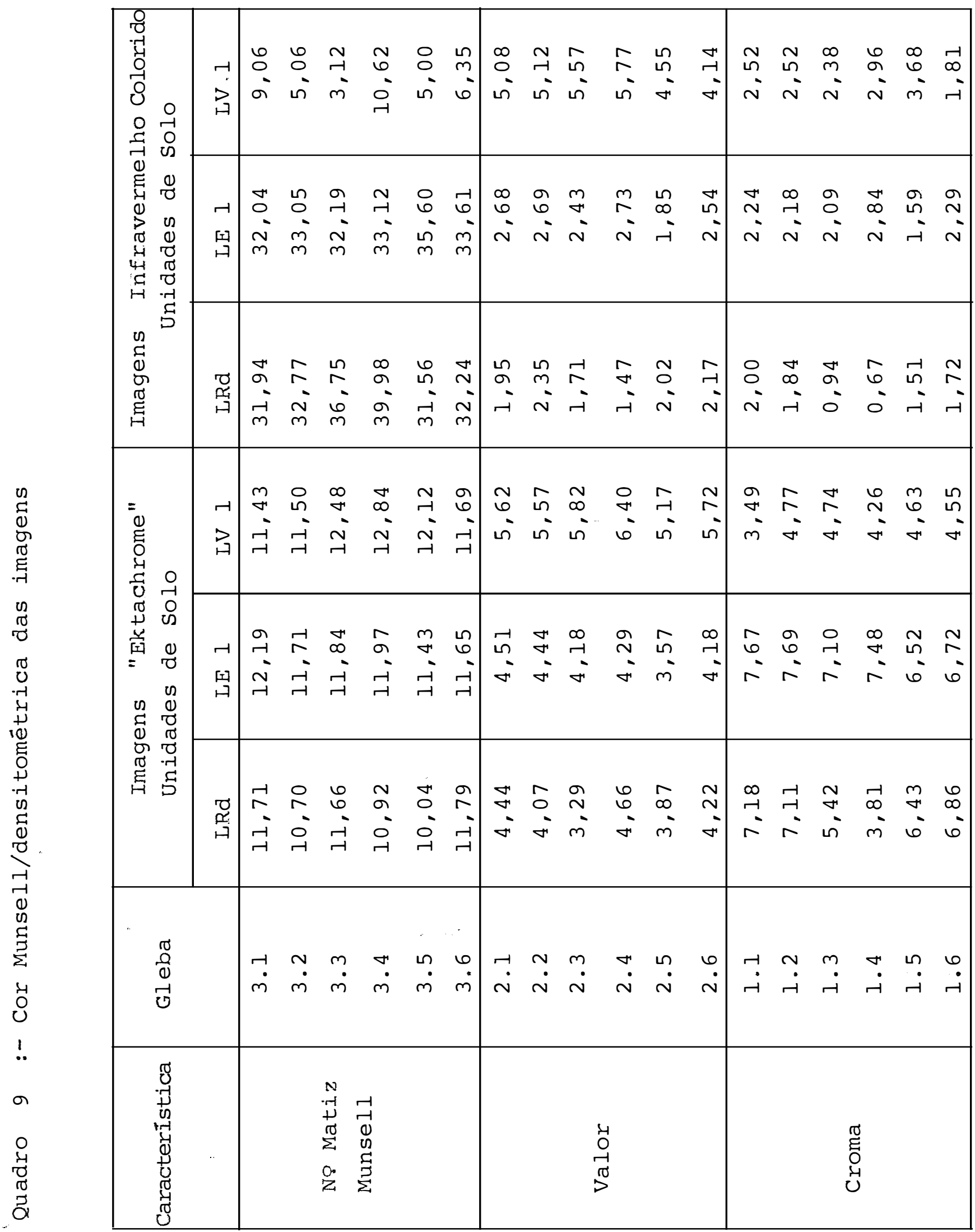


rentes filtros, sendo que cada filtro determina a composicão espectral da luz incidente na imagem ou amostra da qual se deseja avaliar o valor de densidade ótica.

A cor foi determinada pela composição e quantificação da luz transmitida através da imagem, ou refletida pela amostra de solo. A luz resultante, por exemplo, do filtro vermelho, com composição espectral na faixa do vermelho, ao incidir em uma imagem de matiz também vermelho, produzirá altos valores de transmitância e, consequentemente, baixos valores de densidade.

No caso presente, foram avaliadas as cores do solo com matiz "YR" que foram reproduzidas com matiz "YR" nas imagens "ektachrome" e com matiz "GY" nas imagens infravermelho colorido. A única excessão diz respeito à unidade de solo LV 1, cujo matiz "YR" da amostra é acompanhado por altos indices de valor e croma, traduzindo cores bem mais claras, que foram reproduzidas em média pela notação 6,63R 5,04/2,64, nas imagens infravermelho colorido.

Os resultados dos matizes das imagens em relação aos matizes das amostras estão em concordância com as características dos filmes utilizados. Vide Quadro 2, HELLER (1971).

Quanto maiores os valores de densidade ótica, menores são as amplitudes dos valores de reflectância espectral dos solos ou imagens, caracterizada através do registro densitométrico. As amostras úmidas apresentaram reflectância de menor amplitude, concordando com as pesquisas de CIPRA et alii (1971), BOWERS e HANKS (1965) e CONDIT (1970). 
4.2. Avaliação das cores entre cada unidade de solo em confronto com a tabela de Munsell

Na comparação psico-fisiológica das cores obtidas, confrontadas com a tabela de cores de Munsell, verifica-se o seguinte:

Analisando-se os valores médios para as amostras de solo, Quadros 4 e 5, pode-se perceber diferenças marcantes apenas para as notações correspondentes à unidade LV l, sendo difícil a percepção de diferenças em cor para as duas outras unidades.

4.2.1. Amostras secas (valores médios - 6 amostras)

LRd - 2,16 YR 3,21/4,93

$\mathrm{LE} 1-2,00 \mathrm{YR} 3,34 / 5,10$

$\mathrm{LV} 1-2,74 \mathrm{YR} 3,77 / 4,12$

4.2.2. Amostras umedecidas (valores médios - 6 amostras)

LRd - 1,26 YR $2,85 / 3,76$

LE $1-1,31$ YR $2,75 / 4,39$

$\mathrm{LV} 1-2,32 \mathrm{YR} 3,11 / 4,11$

Pelo exame dos Quadros 6 e 7 , com os resultados das cores Munsell/densitométricas das imagens "ektachrome" e infravermelho colorido, pode-se perceber diferenças entre os valores médios de todas as caracteristicas da cor, para todas as unidades de solo estudadas. 
4.2.3. Imagens "ektachrome" (valores médios - 6 glebas )

LRd - 1,14 YR $4,13 / 6,13$

LE $1-1,80$ YR $4,19 / 7,20$

$\mathrm{LV} 1-2,01$ YR $5,72 / 4,41$

4.2.4. Imagens infravermelho colorido (valores médios 6 glebas)

$$
\begin{aligned}
& \text { LRd - 4,20 GY } 1,95 / 1,45 \\
& \text { LE } 1-3,27 \text { GY } 2,48 / 2,20 \\
& \text { LV } 1-6,63 \text { R } 5,04 / 2,64
\end{aligned}
$$

No entanto, verifica-se superposição de valores das características da cor entre as unidades LRd e LE 1, quando se examinam os resultados de cada repetição.

Essa avaliação psico-fisiológica dos resultados da cor Munsell/densitométrica, nas imagens, está de acordo com resultados relatados por OLIVEIRA et alii (*), nos quais, a cor média da unidade LE 1 difere em matiz e croma da cor da unidade LRd, correspondente ao horizonte B.

Nesse particular, algumas hipóteses podem ser aventadas para explicar o fato das imagens apresentarem, em média, diferenças entre essas unidades, quando 0 mesmo não acontece com a cor Munsell/densitométrica das amostras.

(*) OLIVEIRA, J.B.; J.R.F. MENK; J.L. BARBIERI; C.L. ROTTA e W.A. TREMOCOLDI, Levantamento Pedolōgico Semi-detalhado do Estado de são Paulo - Quadrícula de Araras. Campinas Instituto Agronômico (não publicado). 
Essas diferenças poderiam ser explicadas pela influência da estruturação do solo, na sua reflectância, como verificado por Ordov, citado por MYERS (1979) e VALERIO FILHO et alli (1976).

Nesse caso, a densitometria ótica das imagens, com controle dos fatores que influenciam as medidas, estaria avaliando a reflectância espectral relativa dos solos, nas suas condições naturais, o que não acontece com as amostras onde a estrutura do solo foi destruida.

Outra consideração seria relativa aos fatores que influenciam as medidas de densidade, tanto nas imagens quanto nas suas amostras, que poderiam ser responsáveis pelas pequenas diferenças encontradas.

4.3. Avaliação estatística das cores Munsell/densitométricas de cada unidade de solo.

Para a avaliação estatística das notações Mun sell/densitométricas obtidas, para cada unidade de solo, foram considerados os resultados apresentados no Quadro 8 para as notações da cor das amostras secas e umedecidas, bem como no Quadro 9 para as imagens "ektachrome" e infravermelho colorido.

Na análise estatística, foram considerados os resultados da aplicação do teste não paramétrico de Kruskal-Wallis, as "Comparações Múltiplas" e correlações entre as variáveis estudadas.

4.3.1. Cor das amostras de TFSA

O Teste de Kruskal-Wallis mostrou diferenças significativas ao nivel de $1 \%$ de probabilidade para 0 matiz, valor e croma, indicando que pelo menos um dos tratamentos (unidade de solo) diferiu dos demais. 
Nas comparações mūltiplas, foram detectadas diferenças significativas apenas entre os confrontos $|L R d-L V I|$ e $|L E I-L V I|$, não sendo detectadas diferenças significativas entre o confronto |LRd - LE I| para nenhuma das caracteristicas da cor estudadas, conforme mostra o Quadro 10 .

4.3.2. Cor das amostras umedecidas

Apenas o número da matiz de Munsell diferiu entre as unidades de solo, ao nível de 1\% de probabilidade, sendo que o teste não detectou diferenças para o valor e croma. No confronto entre solos não foram detectadas diferenças entre LRd e LE 1. Os confrontos |LRd - LV l| e |LE 1 - LV I| mostraram-se diferentes ao nível de 1\% de probabilidade. No Quadro 11, observa-se que, com o aumento do teor de umidade, houve uma tendência de equalização do valor e croma dos solos.

\subsubsection{Cor das imagens "ektachrome"}

As imagens "ektachrome" apresentaram diferenças significativas apenas para o valor e croma a $1 \%$ de probabilidade. Os confrontos entre solos LRd e LE 1 tambēm não mostraram diferenças significativas. Os demais confrontos $\mid L R d$ - LV I| e |LE 1 - LV I| mostraram-se diferentes a 1\% de probabilidade, como evidencia o Quadro 12.

\subsubsection{Cor das imagens infravermelho colorido}

Matiz, valor e croma mostraram-se diferentes na comparação entre solos, todos com valores de "H" siqnificativos a $1 \%$ de probabilidade.

$$
\text { Foram detectadas diferenças no confronto }
$$

|LRd - LE 1 | para o croma Munsell/densitométrico, porêm a 
10\% de probabilidade, o que pode conferir a essas imagens ligeira vantagem sobre as imagens "ektachrome", para a finalidade em questão. Pesquisas semelhantes de CIPRA (1973), CARNEIRO e AZOLIN (1976), com utilização de composições coloridas e preto-e-branco do MSS-ERTS, também mostraram vantagens no uso das imagens do "infravermelho próximo" sobre as do "visível" para levantamentos de solos.

$$
\text { O confronto LE } 1 \text { - LV } 1 \text { apresentou diferenças }
$$

marcantes apenas no matiz, a 1\% de probabilidade. Nesse confronto, o croma não apresentou diferenças significativas como indica o Quadro 13.

\subsection{Correlações}

As aerofotografias "ektachrome" e infravermetho colorido foram eficientes na caracterização de diferenças entre solos, principalmente quando se considera a cor como uma das caracteristicas distintivas. Com base nas pesquisas de MONTGOMERY et alii (1976), BOWERS e HANKS (1965), SHIELDS et alii (1968), MYERS (1979), PAGE (1974), verifica-se que várias são as características dos solos altamente correlacionadas à sua cor e, consequentemente, responsáveis pela diferenciação tonal caracterizada neste trabalho.

As Figuras 8 e 9 mostram a correlação linear entre as características da cor das amostras de solo em dois teores de umidade e as das correspondentes imagens em aerofoto "ektachrome". Nessas relações foram verificadoos altissimos coeficientes de correlação significativos a 1\% de probabilidade, com 9 pares de valores correspondentes ao matiz, valor e croma, para três unidades de solo. DOMINGUES (1960) relata resultados semelhantes. Verifica-se também, que os coeficientes de correlação entre os valores de densidade ötica da imagem são significativamente mais baixos, como se 
Quadro 10 :- Resultados do teste de Kruskal-Wallis, envolvendo os valores da cor Munsell/densitométrica das amostras de TFSA, para três unidades de solo

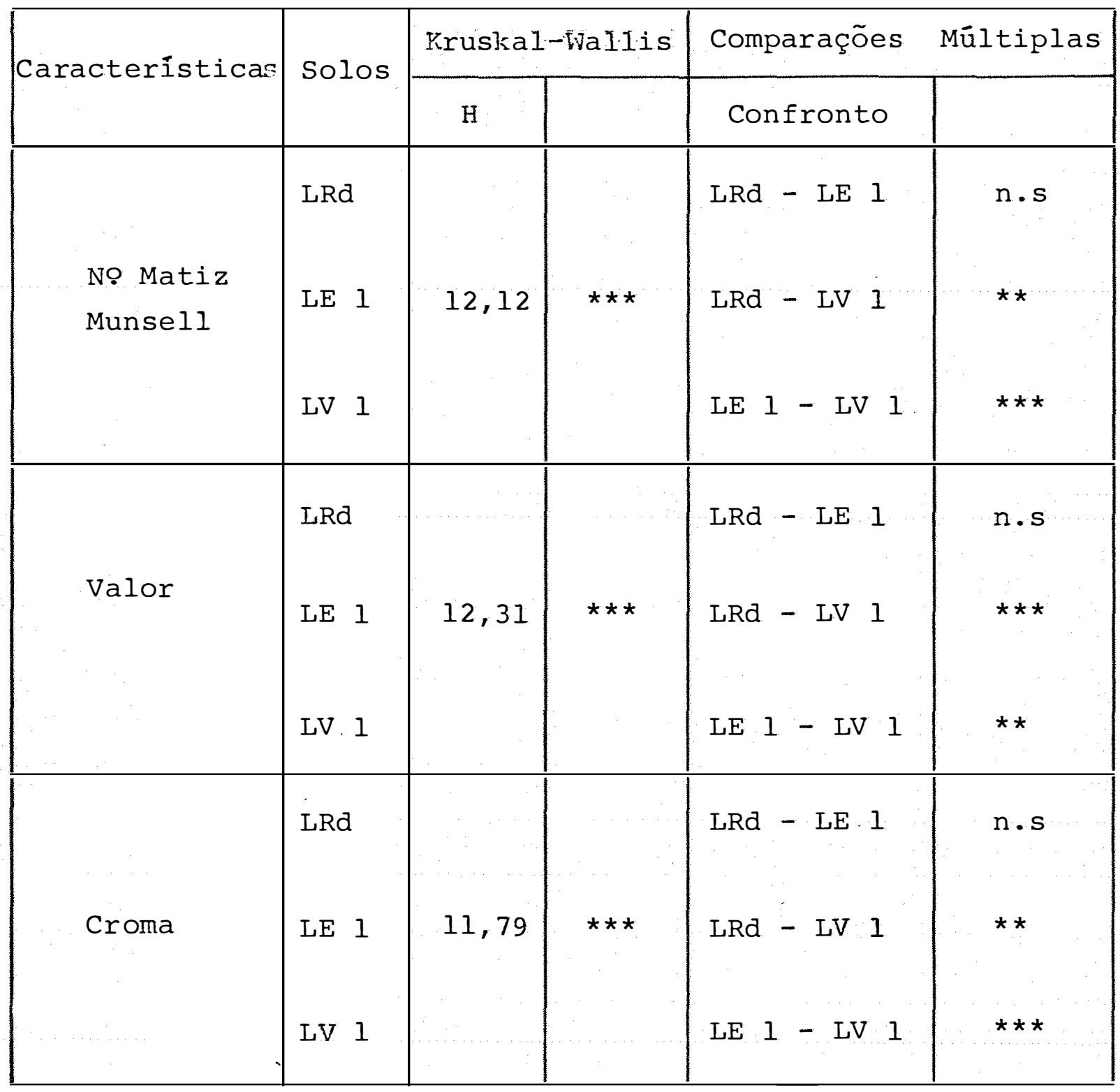

n.s $=$ não significativo

** = Significativo ao nível de 5\% de probabilidade *** = Significativo ao nivel de l\% de probabilidade 
Quadro 11 :- Resultados do teste de Kruskal-Wallis, envolvenvendo os valores da cor Munsell/densitométrica das amostras umedecidas para as três unidades de solo

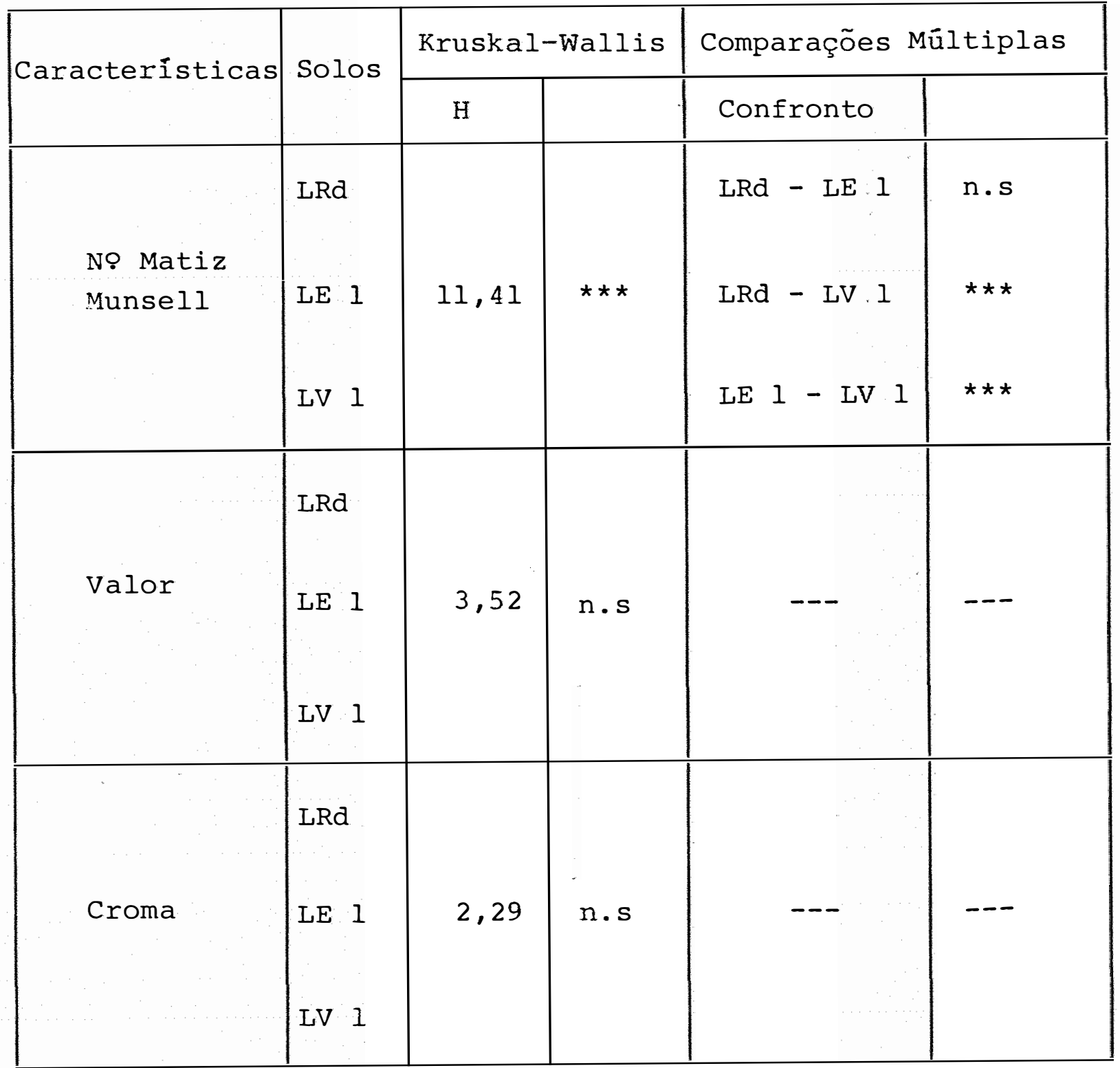

n.s = não significativo

*** = significativo ao nível de lo de probabilidade 
Quadro 12 :- Resultados do teste de Kruskal-Wallis, envolvendo os valores da cor Munsell/densitométrica das imagens "ektachrome", para as três unidades de solo

\begin{tabular}{|c|c|c|c|c|c|}
\hline \multirow{2}{*}{ Características } & \multirow{2}{*}{ Solos } & \multicolumn{2}{|c|}{ Kruskal-Wallis } & \multicolumn{2}{|c|}{ Comparações Múltiplas } \\
\hline & & $\mathrm{H}$ & & Confronto & \\
\hline $\begin{array}{l}\text { No Matiz } \\
\text { Munsell }\end{array}$ & $\begin{array}{l}\text { LRd } \\
\text { LE } 1 \\
\text { LV } 1\end{array}$ & 3,75 & n.s & --- & --- \\
\hline Valor & $\begin{array}{l}\text { LRd } \\
\text { LE } 1 \\
\text { LV } 1\end{array}$ & 11,45 & $\star \star \star$ & $\begin{array}{l}\text { LRd - LE } 1 \\
\text { LRd - LV } 1 \\
\text { LE } 1-L V 1\end{array}$ & $\begin{array}{l}\text { n.s } \\
\star \star \star \\
\star \star \star\end{array}$ \\
\hline Croma & $\begin{array}{l}\text { LRd } \\
\text { LE } 1 \\
\text { LV } 1\end{array}$ & 10,25 & $\star \star \star$ & $\begin{array}{l}\text { LRd - LE } 1 \\
\text { LRd - LV } 1 \\
\text { LE I - LV I }\end{array}$ & $\begin{array}{l}\mathrm{n} . \mathrm{s} \\
\star \star \star \\
\star \star \star\end{array}$ \\
\hline
\end{tabular}

n.s = não significativo

*** = significativo ao nível de 1\% de probabilidade 
Quadro: 13 :- Resultados do teste de Kruskal-Wallis, envolvendo os valores da cor Munsell/densitométrica das imagens infravermelho colorido, para as três unidades de solo

\begin{tabular}{|c|c|c|c|c|c|}
\hline \multirow{2}{*}{ Caracteristicas } & \multirow{2}{*}{ Solos } & \multicolumn{2}{|c|}{ Kruskal-Wallis } & \multicolumn{2}{|c|}{ Comparações Mūtiplas } \\
\hline & & $\mathrm{H}$ & & Confronto & \\
\hline $\begin{array}{l}\text { No Matiz } \\
\text { MunselI }\end{array}$ & $\begin{array}{l}\text { LRd } \\
\text { LE } 1 \\
\text { LV } 1\end{array}$ & 11,42 & $\star * *$ & $\begin{array}{l}\text { LRd - LE } 1 \\
\text { LRd - LV } 1 \\
\operatorname{LE~} 1-\mathrm{LV} 1\end{array}$ & $\begin{array}{l}n . \mathrm{s} \\
\star \star \star \\
\star \star \star\end{array}$ \\
\hline Valor & $\begin{array}{l}\text { LRd } \\
\text { LE } 1 \\
\text { LV } 1\end{array}$ & 13,66 & $\star \star \star$ & $\begin{array}{l}\text { LRd - LE } 1 \\
\text { LRd - LV } 1 \\
L E I-L V I\end{array}$ & $\begin{array}{l}\text { n.s } \\
* * * \\
*\end{array}$ \\
\hline Croma & $\begin{array}{l}\text { LRd } \\
\text { LE } 1 \\
\text { LV } 1\end{array}$ & 9,72 & $\star \star \star$ & $\begin{array}{l}\text { LRd - LE } 1 \\
\text { LRd - LV } 1 \\
\text { LE } 1 \text { - LV } 1\end{array}$ & $\begin{array}{l}\star \\
* \star \star \\
\text { n.s }\end{array}$ \\
\hline
\end{tabular}

n.s = não significativo

* = significativo ao nível de 10\% de probabilidade *** = significativo ao nível de $1 \%$ de probabilidade 
pode observar pelo exame das Figuras 10 e 11.

Ao que parece, a principal explicação para que o coeficiente de correlação entre os valores densitométricos sejam mais baixos que os da respectiva cor é que não existe uma correspondência entre os valores densitométricos para um mesmo filtro. De acôrdo com RIB (1968), o que importa são as relações entre os valores densitomētricos dos diversos filtros, na determinação das características da cor pelo processo utilizado (valores $R, R R, R R R$ ).

As mesmas correlações não foram estabelecidas em aerofotos infravermelho "falsa cor", uma vez que há uma troca das cores reais nesse tipo de filme.

Como os valores densitométricos obtidos com filtro visual avaliam a resposta tonal em toda a faixa de sensibilidade espectral do filme utilizado, existe uma correlação linear entre os valores densitométricos obtidos com esse filtro, para os dois tipos de imagem, conforme ilustra a Figura 12 .

Analisando os resultados dessa correlação a interpretação que parece correta é que, quanto mais baixos os valores de $\mathrm{R}$, maiores seriam as evidências de uma resposta espectral diferencial entre essas imagens. Os valores densitomētricos absolutos são muito diferentes, como se pode verificar nos Quadros 6 e 7 , mas o coeficiente de correlação dos 18 pares de valores é significativo a 1응 de probabilidade, não sendo porēm, tão alto que não possa evidenciar pequenas diferenças entre os registros tonais.

Pelo exame dos Quadros 14 e 15 pode-se, da mesma forma, verificar que são bastante altos os coeficientes de correlação entre os valores densitomētricos obtidos em diferentes filtros, para uma mesma imagem. Sendo alta a correlação entre esses valores, pode-se esperar que a correlação entre a reflectāncia registrada através das medidas 
densitométricas nas diversas faixas do espectro eletromagnético,e cor do solo, também não apresente grandes diferenças. Em outras palavras, a variabilidade dos valores " $R$ ", nos dois casos, é correlacionada. Nos Quadros 14 e 15 pode-se verificar uma menor variabilidade dos valores " $R$ " nas imagens infravermelho $(0,80$ - 0,90) para uma variabilidade entre filtros nessa imagem, extremamente pequena $(0,97-0,99)$ evidenciando cores muito escuras.

Apesar da pequena variabilidade, encontraram-se coeficientes " $R$ " ligeiramente maiores na região espectral do "verde", avaliada pelo filtro verde nas fotos "ektachrome" e filtro azul nas fotos infravermelho.

Considerando as caracteristicas da cor isoladamente, nas imagens "ektachrome", o "matiz" e "croma" estão mais correlacionados aos valores densitométricos dos filtros azul e verde e "valor" com filtro visual. Nas imagens infravermelhas, o "matiz" e "croma" apresentam-se mais correlacionados ao filtro azul e "valor" aos filtros visual e vermelho, indistintamente. Esses resultados, aparentemente estão em desacordo com os relatados por Obukhov e Orlov, citados por MYERS e ALLEN (1968), segundo os quais existem maiores correlações de reflectância com a cor na faixa espectral do vermelho e infravermelho.

No entanto, as pesquisas de CROWN e PAWLUK (1974) mostram que as correlações da reflectância espectral com a cor na faixa do visivel são maiores que no infravermelho próximo, sendo esta última faixa mais correlacionada a outras caracteristicas dos solos.

Deve-se ressaltar que as correlações apresentadas neste trabalho, dizem respeito a registros tonais em imagens confrontadas com as características da cor dos solos, enquanto que, nas pesquisas desenvolvidas por esses autores, os registros de reflectância correlacionados foram avaliados diretamente no solo. 


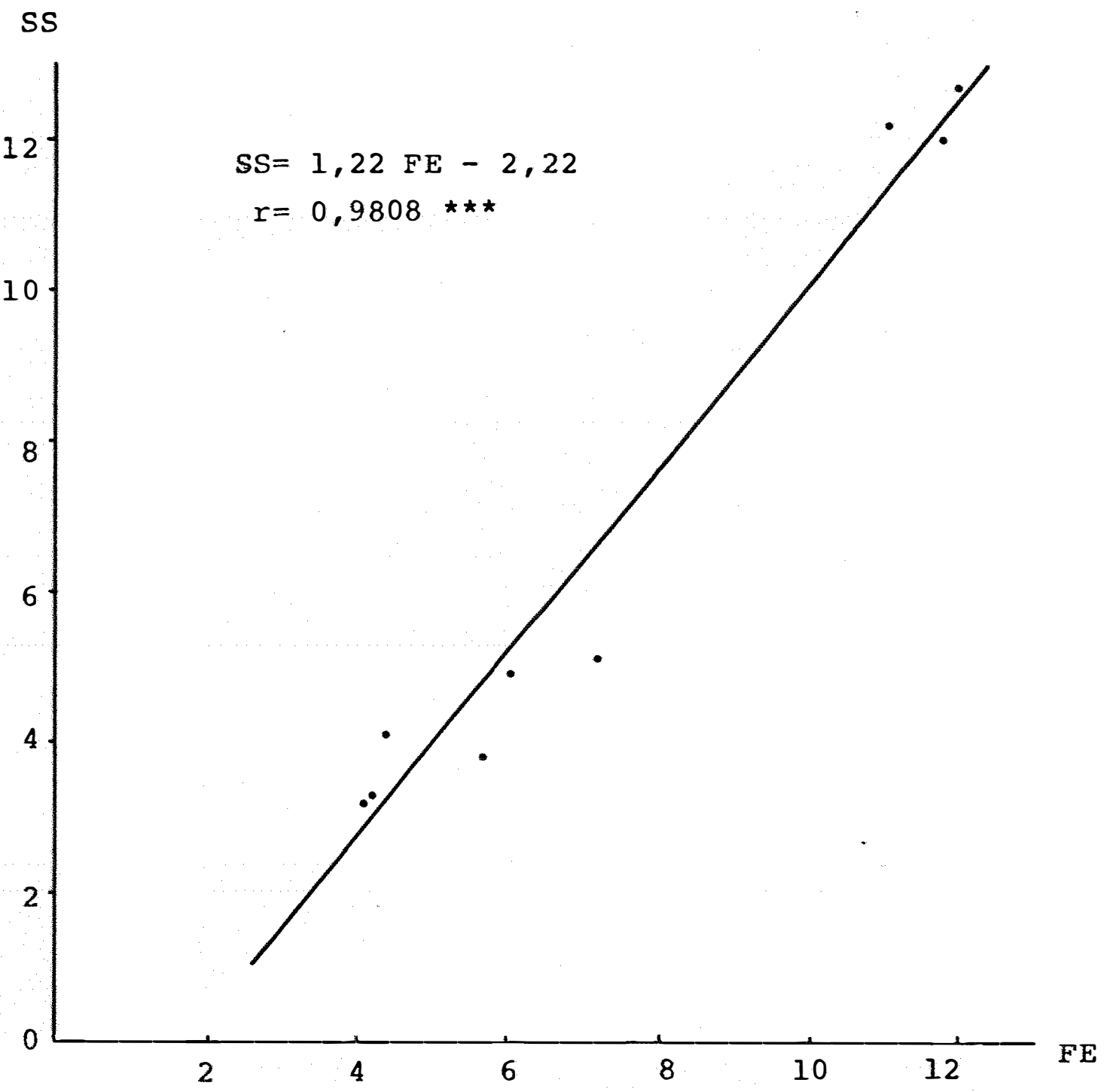

*** Significativo ao nível de $1 \%$ de probabilidade

Fig.8 - Relação funcional entre cor (Matiz, Valor e Croma) média das amostras de solo seco (TFSA), (SS), e cor média das correspondentes imagens em fotos "ekta chrome" (FE), para as très unidades de solo estu dadas. 


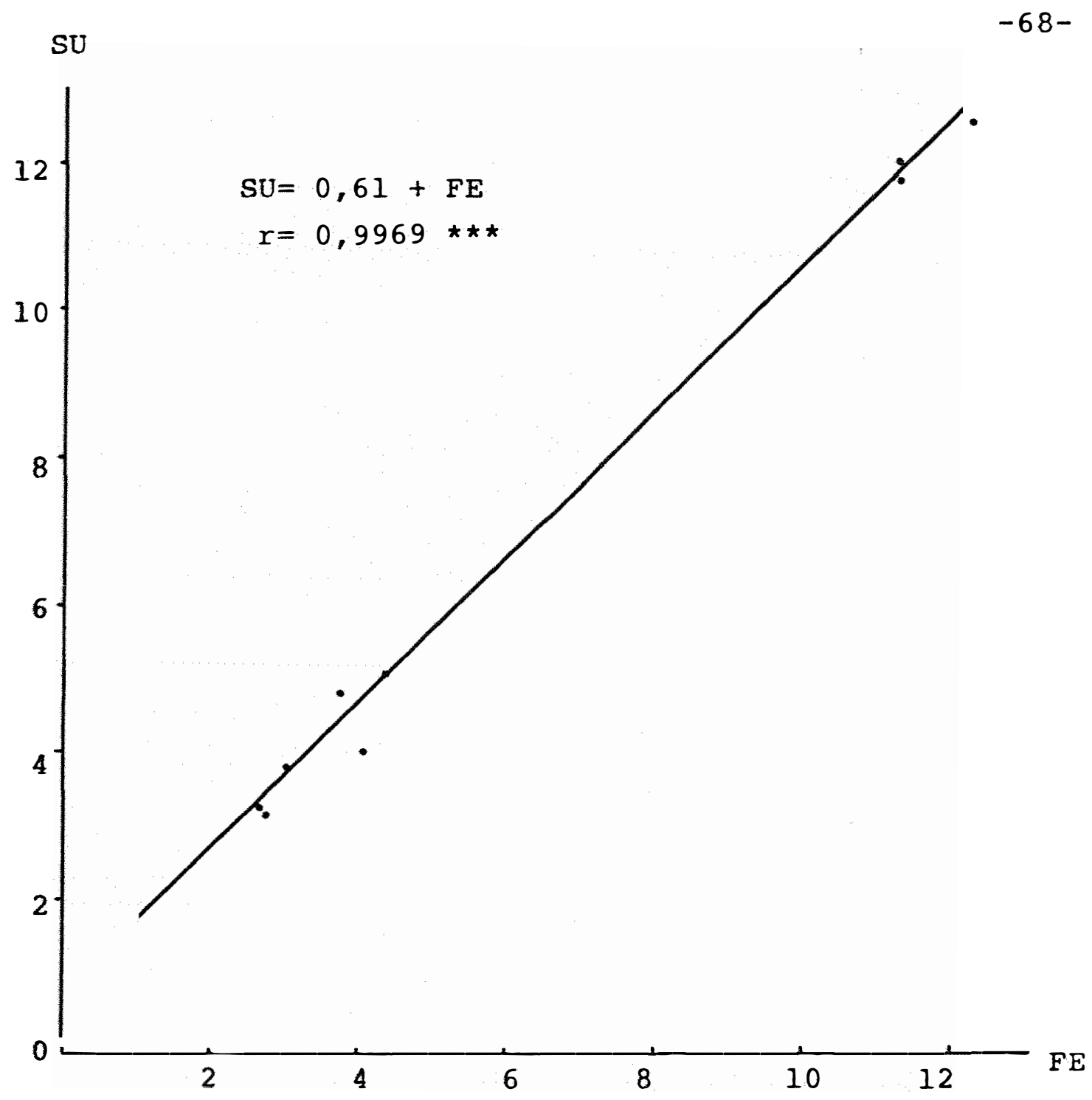

*** Significativo ao nível de $1 \%$ de probabilidade

Fig.9 - Relação funcional entre cor das amostras umedecidas (Matiz, Valor e Croma), (SU), e cor das correspondentes imagens "ektachrome" (FE), para as trēs uni dades de solo estudadas. 


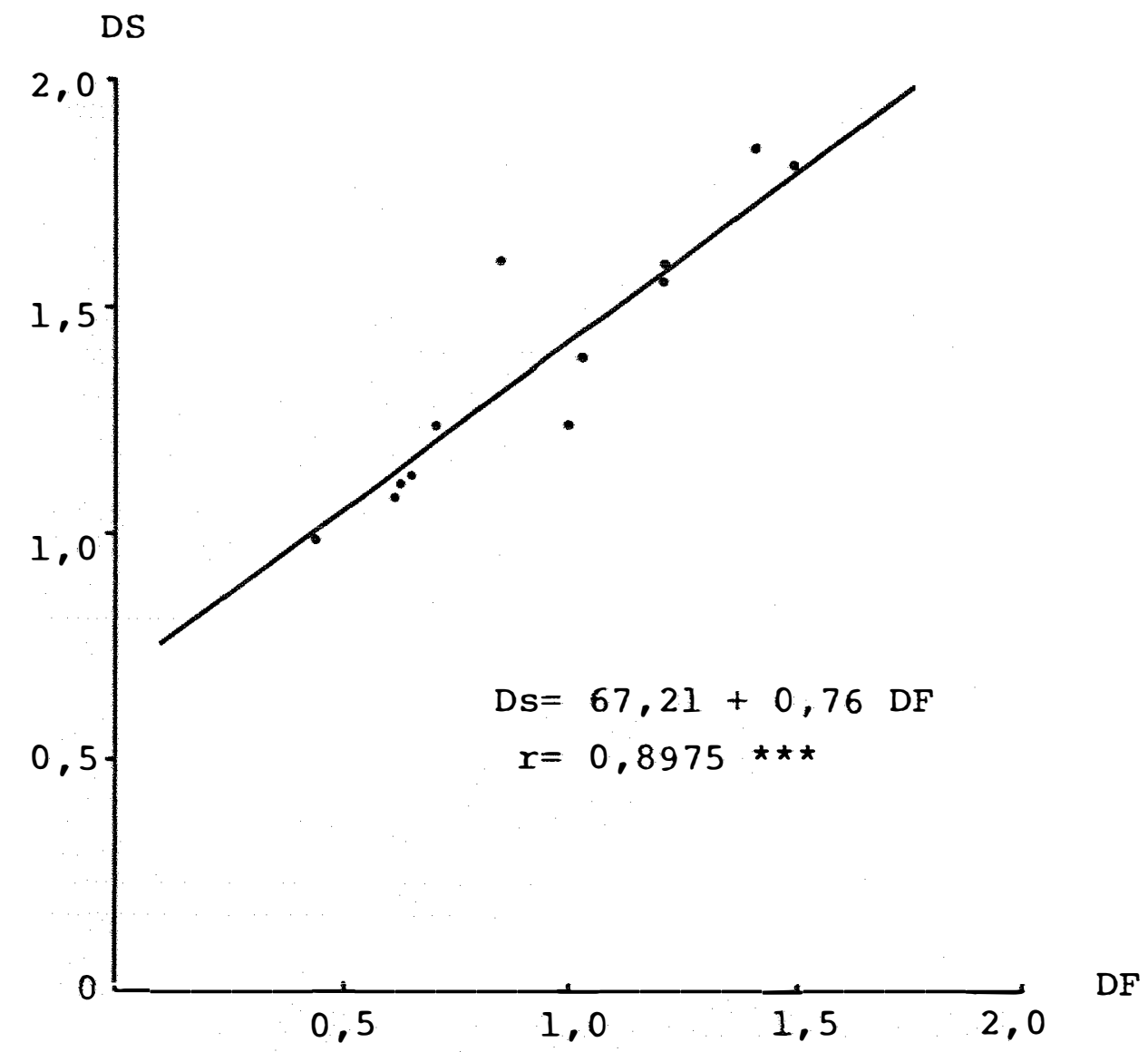

** Significativo ao nível de $1 \%$ de probabilidade

Fig.10 - Relação funcional entre densitometria ótica (DS) das amostras de solo (TFSA) e densitometria ótica das correspondentes imagens em fotos "ektachro me (DF) para 12 leituras médias de 6 repetições para cada unidade de solo estudada. 


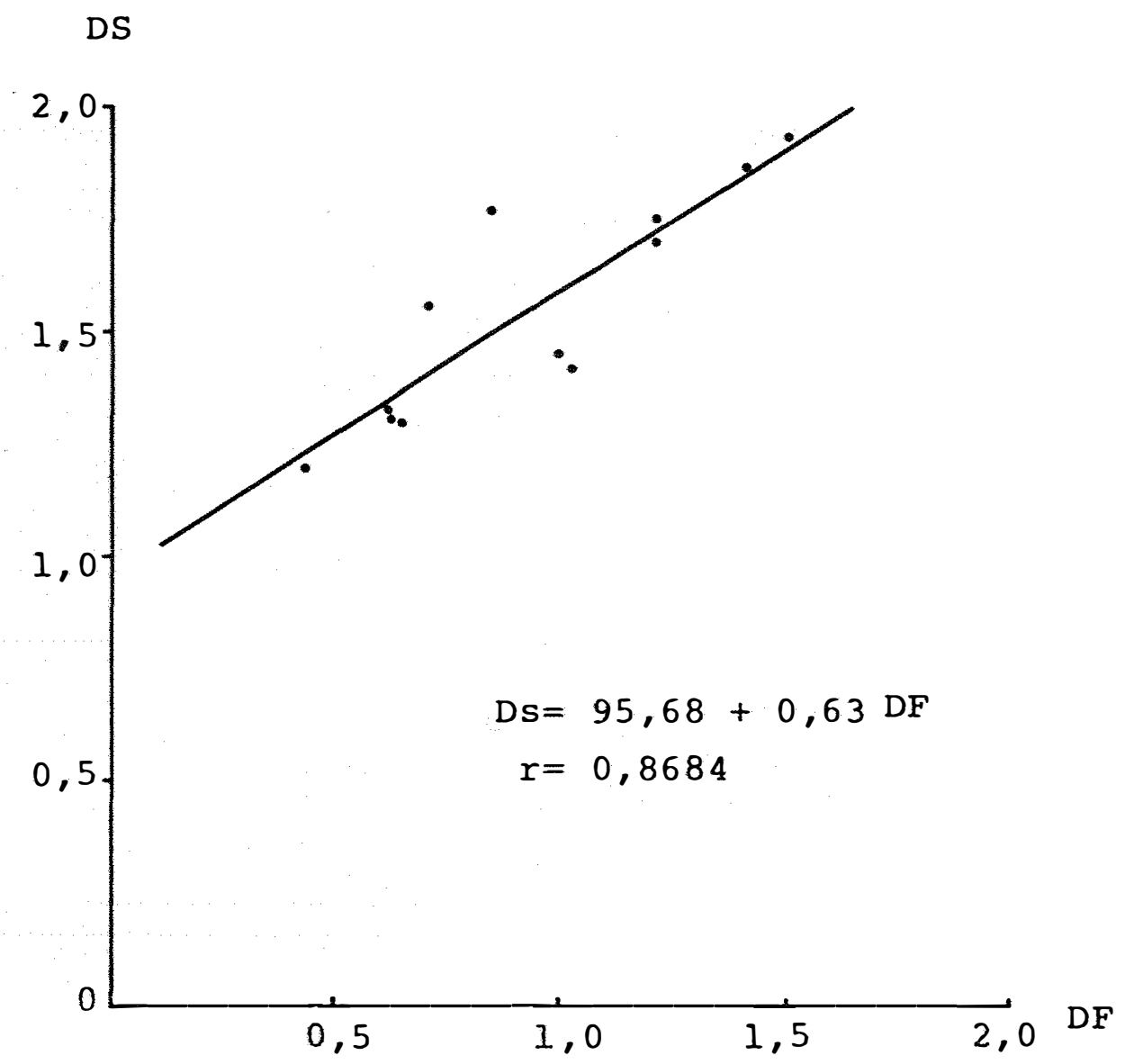

** Significativo ao nível de 1\% de probabilidade

Fig.ll - Relação funcional entre densitometria ótica (DS) das amostras de solo (Solo umedecido) e densito metria ótica das correspondentes imagens em fotos "ektachrome" (DF) para 12 leituras provenientes de 6 repetições para cada unidade de solo. 


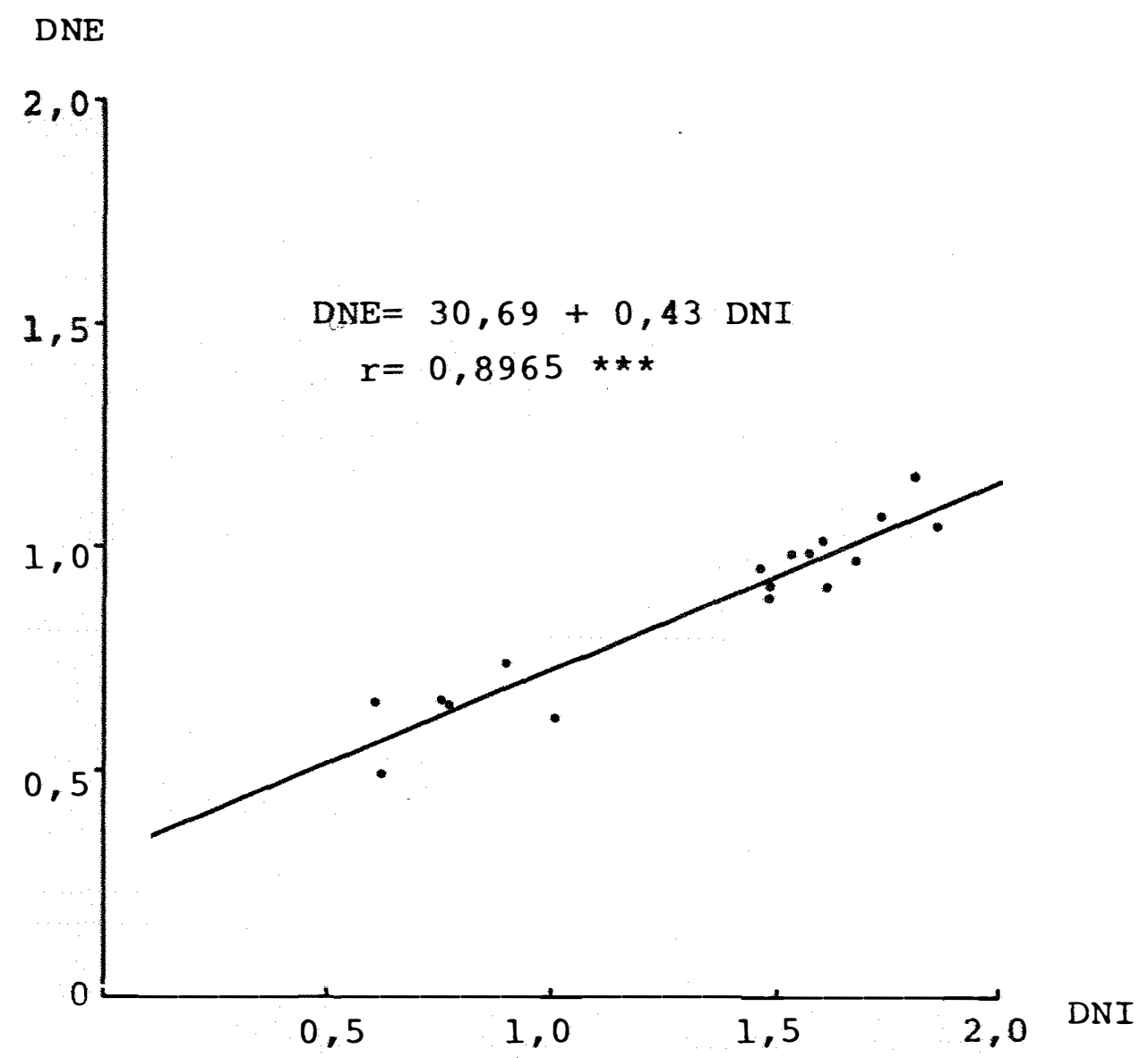

เ*** Significativo ao nível de $1 \%$ de probabilidade

Fig.12 - Relação funcional entre valores de densidade ótica de filtro visual em fotos "ektachrome" (DNE) e medidas de densidade ótica de filtro visual das correspondentes imagens em fotos infravermelho (DNI). 
Quadro 14 :- Matriz de correlaçõessimples - densitometria em aerofotos "ektachrome" e cor das amostras de TFSA, (Valores $R^{*}$ para 18 pares de variáveis)

\begin{tabular}{|l|c|c|c|c|c|c|c|}
\hline \multicolumn{2}{|c|}{ Densitometria em aerofotos "ektachrome" } & Cor das amostras de TFSA \\
\hline Filtros & Vermelho & Verde & Azul & Visual & Matiz & Valor & Croma \\
\hline Vermelho & --- & 0,9017 & 0,8441 & 0,9672 & $-0,7058$ & $-0,7086$ & 0,7744 \\
Verde & -- & -- & 0,9870 & 0,9601 & $-0,8705$ & $-0,7602$ & 0,8907 \\
Azul & -- & -- & -- & 0,9308 & $-0,9033$ & $-0,7528$ & 0,8713 \\
Visual & --- & -- & -- & -- & $-0,7943$ & $-0,7850$ & 0,8329 \\
\hline
\end{tabular}

* Significativos a $1 \%$ de probabilidade 
Quadro 15 :- Matriz de correlações simples - densitometria em aerofotos infravermelho colorido e cor das amos tras de TFSA (valores $R^{*}$ para 18 pares de variáveis)

\begin{tabular}{|l|c|c|c|c|c|c|c|}
\hline \multicolumn{2}{|l}{$\begin{array}{l}\text { Densitometria em aerofotos infraver } \\
\text { melho colorido }\end{array}$} & \multicolumn{2}{|l|}{ Cor das amostras de TFSA } \\
\hline Filtros & Vermelho & Verde & Azul & Visual & Matiz & Valor & Croma \\
\hline Vermelho & --- & 0,9908 & 0,9886 & 0,9960 & $-0,8806$ & $-0,8669$ & 0,8129 \\
Verde & -- & -- & 0,9792 & 0,9970 & $-0,8624$ & $-0,8394$ & 0,8012 \\
Azul & -- & -- & --- & 0,9790 & $-0,9086$ & $-0,8438$ & 0,8520 \\
Visual & --- & -- & -- & -- & $-0,8634$ & $-0,8577$ & 0,7966 \\
\hline
\end{tabular}

* Significativos a $1 \%$ de probabilidade 
Analisando as características da cor em correlação múltipla com a densitometria : ótica nos quatro filtros, para os dois tipos de imagens estudados, verifica-se o seguinte:

a) Fotos "ektachrome"

\begin{tabular}{c|c|c}
\hline Cor & Variáveis independentes & $\mathrm{R}^{\star}$ \\
\hline Matiz (M) & $\mathrm{x}_{1} ; \mathrm{x}_{2} ; \mathrm{x}_{3} ; \mathrm{x}_{4}$ & 0,8448 \\
Valor (V) & $\mathrm{x}_{1} ; \mathrm{x}_{2} ; \mathrm{x}_{3} ; \mathrm{x}_{4}$ & 0,6486 \\
Croma (C) & $\mathrm{x}_{1} ; \mathrm{x}_{2} ; \mathrm{x}_{3} ; \mathrm{x}_{4}$ & 0,8129 \\
\hline
\end{tabular}

b) Fotos infravermelho colorido

\begin{tabular}{c|c|c}
\hline Cor & Variáveis independentes & $\mathrm{R}^{*}$ \\
\hline Matiz (M) & $\mathrm{x}_{1} ; \mathrm{x}_{2} ; \mathrm{x}_{3} ; \mathrm{x}_{4}$ & 0,8457 \\
Valor (V) & $\mathrm{x}_{1} ; \mathrm{x}_{2} ; \mathrm{x}_{3} ; \mathrm{x}_{4}$ & 0,7840 \\
Croma (C) & $\mathrm{x}_{1} ; \mathrm{x}_{2} ; \mathrm{x}_{3} ; \mathrm{x}_{4}$ & 0,7658 \\
\hline
\end{tabular}

Onde:

$\mathrm{x}_{1}=100 \mathrm{x}$ (Leitura densitométrica do filtro vermelho)

$x_{2}=100 \times$ (Leitura densitométrica do filtro verde)

$x_{3}=100 \times$ (Leitura densitométrica do filtro azul)

$\mathrm{x}_{4}=100 \mathrm{x}$ (Leitura densitométrica do filtro visual)

* Significativos a $1 \%$ de probabilidade 
Os coeficientes de correlação múltipla são altos e significativos a 18 de probabilidade, tanto para imagens "ektachrome" como infravermelho colorido.

Considerando as características "matiz". e "croma" da cor, em fotos "ektachrome", confirmam-se as pesquisas de CROWN e PAWLUK (1974), que mostram maiores coeficientes de correlação entre cor e reflectância espectral na faixa do visivel.

Os maiores valores de $\mathrm{R}$ são para o "matiz" , possibilitando até sua determinação através das equações de regressão, quando se restringirem ao material utilizado.

São as seguintes as equações de regressão para os dois tipos de imagem:

$$
\begin{aligned}
& \text { a) Fotos "ektachrome" } \\
& M=13,77-0,0179 x_{1}+0,0197 x_{2}-0,0281 x_{3}+0,0121 x_{4} \\
& V=4,28+0,0203 x_{1}-0,00214 x_{2}+0,00276 x_{3}-0,0242 x_{4} \\
& C=3,18-0,0194 x_{1}+0,0447 x_{2}-0,0174 x_{3}+0,0021 x_{4} \\
& M=13,45+0,0072 x_{1}+0,0109 x_{2}-0,0156 x_{3}-0,0090 x_{4} \\
& V=3,66-0,0086 x_{1}+0,0148 x_{2}+0,0017 x_{3}-0,0097 x_{4} \\
& C=2,76-0,0186 x_{1}-0,0103 x_{2}+0,0279 x_{3}+0,0118 x_{4}
\end{aligned}
$$


4.5. Sugestões para novas pesquisas

A experiência adquirida no desenvolvimento deste trabalho sugere a realização de pesquisa relacionando a densitometria ótica em aerofotos ou amostras de solo, com as caracteristicas físico-químicas dos solos.

Desenvolver estudos para verificar quais, as características dos solos que são mais correlacionadas à sua cor.

Estabelecer correlações entre densitometria ótica em amostras de solo e reflectância espectral, seja em condições naturais ou de laboratório.

Estabelecer correlações entre densitometria ótica em aeroimagens e reflectância espectral em condições de campo através de espectroradiômetros.

Desenvolver estudos comparativos entre aerofotos "ektachrome", infravermelho colorido e pancromáticas para levantamentos de solo, em termos da relação custo/benefício.

Desenvolver pesquisa para avaliar quais as características das amostras de solo que influem nas suas medidas de densidade ótica como processo para estabelecer a cor Munsell/densitométrica. 
5. CONCLUSÕES

Pela análise dos resultados obtidos, em confronto com a literatura, pode-se tirar as seguintes conclusões :

Através da caracterização densitométrica sobre as aerofotografias "ektachrome" e infravermelho colorido foi possivel detectar-se diferenças entre solos, principalmente quando a cor, e as características intrínsecas do solo a ela relacionadas, foram importantes nessa diferenciação, onde outros tipos de imagens e critérios estudados anteriormente mostraram-se ineficientes.

Embora as imagens infravermelho colorido tenham-se mostrado ligeiramente mais eficientes no registro da reflectância espectral diferencial através da cor, as diferenças observadas não são suficientes para recomendar uma delas em substituição à outra, tendo em vista o critério de tonalidade ou cor na caracterização dos solos estudados.

Apesar dos muitos fatores que influem no registro tonal ou de cores em fotografias aéreas, torna-se possivel reduzir em muito a sua influência através dos métodos utilizados neste trabalho, tornando a cor, um importante critério em fotointerpretação aplicada a solos de regiões tropicais. 
Em solos com elevados teores de umidade são menores as possibilidades de se detectar diferenças em cor, sendo menor a reflectância no espectro eletromagnético, são consequentemente maiores as medidas densitométricas em imagens fotográficas.

Foram verificadas altas correlações entre a cor registrada em aeroimagens "ektachrome" e a cor do solo, determinada em amostras de terra fina, revelando não apenas fidelidade na reprodução das cores pelo filme utilizado, mas as possibilidades de se usar com muito sucesso o critério de tonalidade ou cor em fotopedologia.

Foram verificadas altas correlações entre densitometria ótica de faixas espectrais das aeroimagens e a cor Munsell/densitométrica das unidades de solo estudadas.

Foram encontradas maiores correlações das características da cor com os valores absolutos de reflectância, avaliada pela densitometria das imagens nas faixas espectrais do visivel, do que no infravermelho próximo. 
6. LITERATURA CITADA

ALMEIDA, F.F.M. Os fundamentos geológicos do relevo paulista. Boletim no 41 do Instituto Geográfico e Geológico do Estado de São Paulo, pp. 167-262 - 1964.

AMARAL, A.Z. e AUDI, R. Fotopedologia, In: MONIZ, A.C. Elementos de Pedologia. São Paulo, Editora da USP, Cap. 35 p. 429-442 - 1972 .

AMARAL, G. Sensores Remotos. Aplicações em Geociências, Instituto de Geociências - USP - 114 p. - 1975.

BOWERS, S.A. and HANKS, R.J. Reflection of Radiant Energy From Soils. Soil Science V. 180 (2) p. 130-138 - 1965.

BRASIL. Instituto Brasileiro de Geografia, Carta do Brasil Escala 1:50.000. Folha Topográfica de Araras - 1969.

CAMPOS, H. Estatística Experimental, Não-Paramétrica. Departamento de Matemática e Estatística E.S.A. "Luiz de Queiroz" USP 343 p. - 1979. 
CARNEIRO, M.R. e AZOLIM, M.A.D. Utilização de imagens MSS do ERTS-l em levantamentos de solos em comparação com fotografias aéreas verticais. Revista Centro Ciências Rurais $5(1): 55-66-1976$.

CARROLL, D.M. Remote Sensing techniques and their application to soil science: Part.I - The Photographic sensors. Soil and Fertilizers 36 (7) : 259-266 - 1973.

CARROLL, D.M. Remote sensing techniques and their application to soil science: Part II - The non photographic sensors Soils and Fertilizers 36 (8) : 313-320 - 1973.

CIPRA, J.E. Mapping Soil Association Using ERTS MSS. Data. Conference on Machine Processing of Remotely Sensed Data. LARS - Purdue University. West Lafayette. Indiana. 10p. 1973.

CIPRA, J.E.; BAUMGARDNER, M.F.; STONER, E.R. and MAC DONALD, R.B. Measuring radiance characteristics of soil with a field spectroradiometer. Soil Science of America Proceedings $35(6)$ : 1014-1017 - 1971.

CIPRA, J.E.; SWAIN, P.H.; GILL, J.H.; BAUGARDNER, M.F.;KRISTOF, S.J. Definition of spectrally separable classes for soil survey. In: Procedings of eighth international symposium on remote sensing of enviromment Ann Arbor. University of Michigan, p. 765-770 - 1972.

COLWELL, R.N. Uses and limitations of multispectral remote sensing. Proceedings of 4 th Symposium on Remote Sensing of the Environment. pp7I-100. University of Michigan 1966 . 
CONDIT, H.R. The Spectral Reflectance of American Soils. In Phot. Eng.-Amer. Society of Phot. V-36 9 (955-965) - 1970.

CROWN, P.H. and PAWLUK, S. Spectral Signatures From Selected Soils in the Edmonton Vegreville area. Second Canadian Symposium on Remote Sensing, University of Guelph, Ontario $p(449-461)-1974$.

DOMINGUES, O. A Comparative Analysis of Color and Black-and-White Aerial Photography. as Aids in the Mapping of Soils in Wildland Areas. In: Manual of Photographic Interpretation. Chap 5 appendix A. - p. 398-402 - 1960.

FORSGARD, F.C. and WHITTEMORE, C.M. Color Aerial Films. In: Manual of Color Aerial Photography. Am. Soc. of Phot. Chap. IV - p (196-208) - 1968.

FRANÇA, G.V. Interpretação fotográfica de bacias e redes de drenagem aplicada a solos da região de Piracicaba. Piracicaba, ESALQ/USP. 151 p. (Tese de Doutoramento) - 1968.

GARCIA, G.J. e MARCHETTI, D.A.B. Fotointerpretação da Vegetação através da Densitometria. Anais da ESALQ, Vol. 34 1977 (no prelo).

HELLER, R.C. Imaging With Photographic Sensors. In: Remote Sensing. National Academy of Sciences Washington, D.C. 1971.

HOFFER, R.M.; ANUTA, P.E.; PHILLIPS, T.L. Automatic Data processing, multiband and multiemulsion digitalized photos Laboratory for applications of remote Sensing - Photogrammetric Engineering 38 (10) 989-1001 - 1972. 
HOFFER, R.M. and JOHANNSEN. Ecological Potentials in Spectral signature analysis. In: Remote sensing in Ecology, p.1-29 University of Georgia. Press, Athens - 1969.

INPE. B. Divulg. Banco Dados - São José dos Campos, 1 (9) : 28-37. - 1975 .

INSTITUTO GEOGRAFICO E GEOLÓGICO, ESTADO DE SÃO PAULO. Mapa Geológico do Estado de São Paulo. (Escala 1:1.000.000) 1974 .

KODAK PUBLICATION No Z-22-ED. Basic Photographic Sensitometry Workbook Eastman Kodak Company - 1971.

LUEDER, D.R. Aerial Photographic Interpretation: Principles and applications." New York, Mc. Graw-Hill, 462p. - 1959.

MATHEUS, H.L.; CUNNINGHAN, R.L.; CIPRA, J.E. and WEST, T.R. Application of Multispectral Remote Sensing to Soil Survey Research in Southeastern Pennsylvania. Soil Science Society of America Proceedings. Vol 37, no 1 1973.

MEYER, M.P. Techniques for Ektachrome IR transparencies. Phot. Eng. 35:1111-1114 - 1969.

MONTGOMERY, O.L.; BAUMGARDNER, M.F. and WEISMILLER, R.A. An Investigation of the Relationship between spectral Reflectance and the Chemical, Physical and Genetic characteristics of soils. Laboratory for Application of Remote Sensing. Purdue University. West Lafayette - Indiana USA 147p. - 1976. 
MYERS, V.I. Crops and Soils In: Manual of Remote Sensing. American Society of Photogrammetry. Vol II. Ch.22 p. $1715-1813$ - 1979 .

MYERS, V.I. and ALLEN, W.A. Eletroopical Remote Sensing Methods as non Destrutive testing and mesuring Techniques in Agriculture. Applied Optics 7:1819-1838 - 1968.

OLIVEIRA, J.B.; J.R.F. MENK e C.L. ROTTA Levantamento pedológico semi-detalhado do Estado de são Paulo - Quadrícula de Campinas. Rio de Janeiro, Instituto Brasileiro de Geografia. - 1979 (no prelo).

PAGE, N.R. Eatimation of organic matter in Atlantic Coastal Plain Soils with color-difference meter. Agronomy Journal 66:652-653 - 1974 .

PARKS, W.L. and BODENHEIMER, R.E. Delineation of major association using ERTS-1 imagery In: NASA, Symposium on significant results obtained from the earth resources technology satellite-l. New Carrollton Mar. V.l Sec. A, p. $121-126$ - 1973 .

RAY, R.G. Fotografias aēreas na interpretação e mapeamento geológico. Traduzido por Jesuíno Felicíssimo Jr. (U.S. Geological Survey Professional paper 373, 1960) São Paulo, Instituto Geogräfico e Geológico - 1963.

RAY, R.G. \& FISCHER, W.A. Quantitative photography: a Geological Research. Tool. Photogrammetric Engineering 26:143$160-1960$. 
RIB, H.T. Color Measurements - In: Manual of Colôr Aerial Photography Am. Soc. of Phot. Chap. 1 (12-24) - 1968.

SCARPACE, F.I. Densitometry on multi-emulsion imagery. Photogrammetric Engineering and Remote Sensing 44:1279 1978 .

SCARPACE, F.L. and FRIEDERICHS, G.A. Method of determining spectral analytical dye densities. Photogrammetric Engineering and Remote Sensing 44:1293 - 1978 .

SETzER, J. Atlas Climático e Ecolōgico do Estado de são Paulo. São Paulo, Comissão Interestadual da Bacia Paraná - Uruguài. 6lp. - 1966 .

SHIELDS, J.A.; E.A. PAUL; R.J. St. ARNARD and HEAD, W.K. Spectrophotometric mensurement of soil color and its relationship to moisture and organic matter. Canadian Journal of Soil Science 48 (3) : 271-280 - 1968.

SOIL CONSERVATION SERVICE - Aerial Photo Interpretation in classifying and mapping soils. Agriculture Handbook washington DC. 90p. - 1966 .

STEINER, D. and HAEFNER, A. Tone Distortion for Automated Interpretation In Photogrammetric Engineering Amer. Society of Phot. Vol. 31:269-280 - 1965 .

STRANDBERG, C.H. The Language of Color - In: Manual of Color Aerial Photography - Am. Soc. of Phot. Chap. 1 (3-12) 1968 .

VAIERIO FILHO, M.; HIGA, N.T.; CARVALHO, V.C. Avaliação das imagens orbitais (LANDSAT-1) como base para levantamento solos. Tese de Mestrado em Sensoriamento Remoto e Aplicações - são José dos Campos - INPE - (912-TPT/030) - 1976. 